
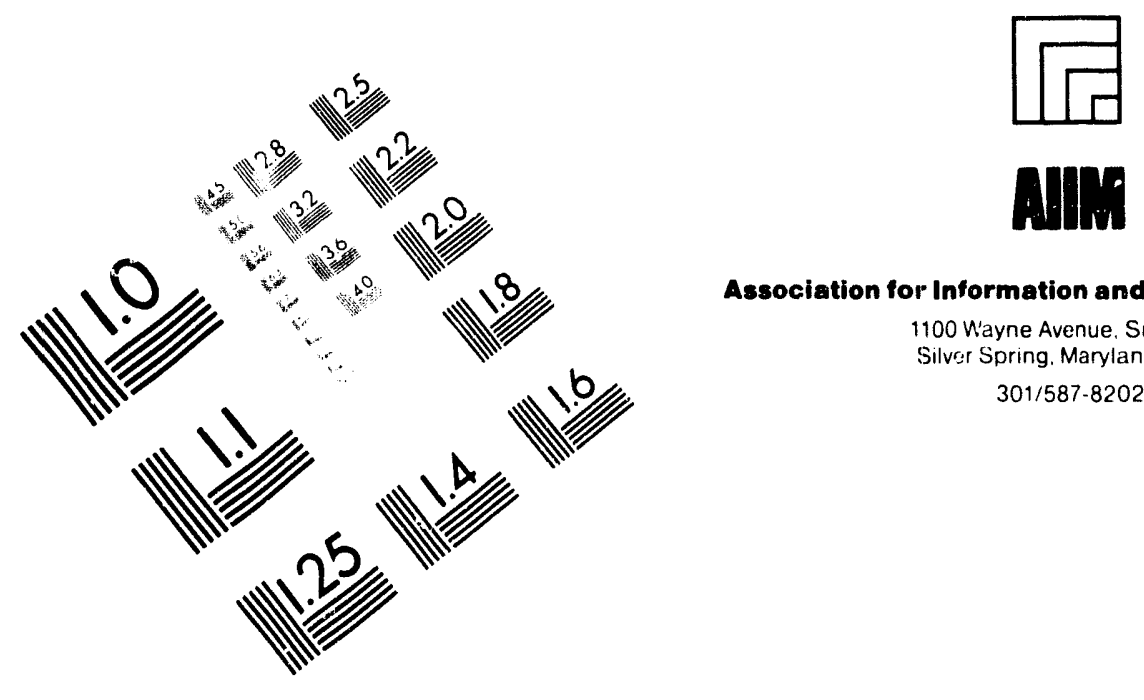

Association for Information and Image Management

1100 W'ayne Avenue. Sulte 1100

Silver Spring. Maryland 20910

301/587-8202

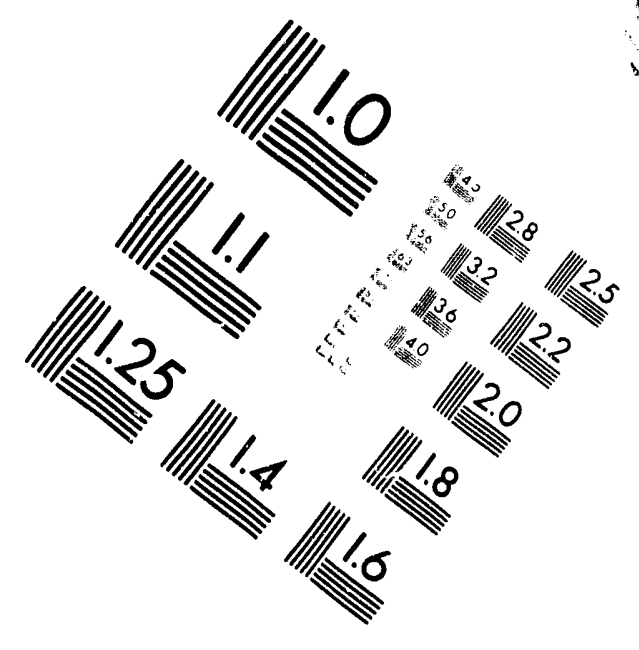

\title{
Centimeter
}

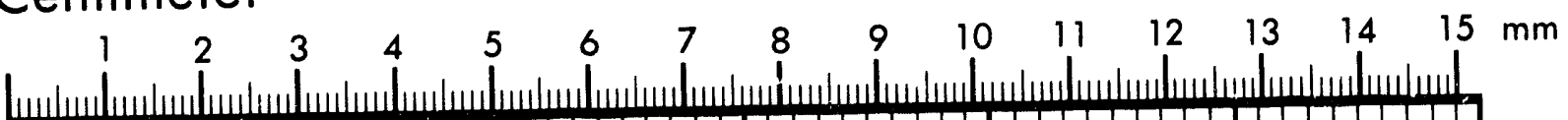

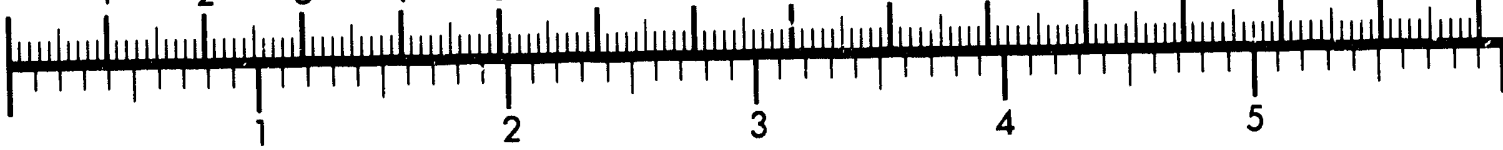

Inches
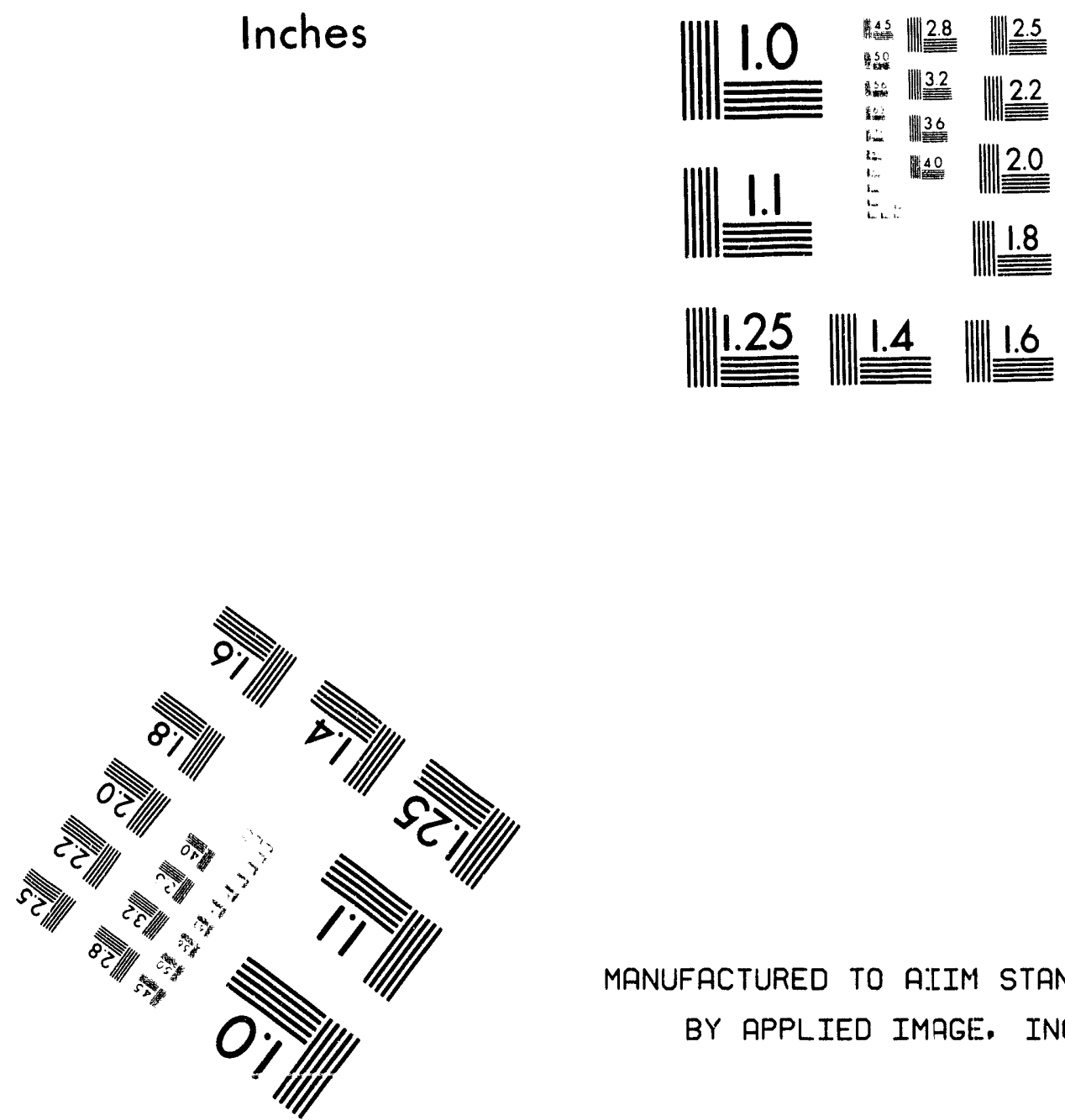

MANUFACTURED TO A:LIM STANDARDS

BY APPLIED IMAGE. INC.

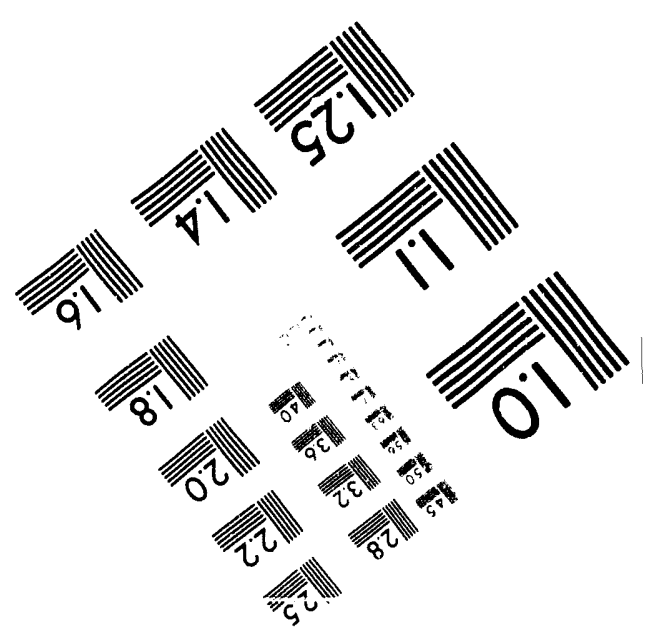



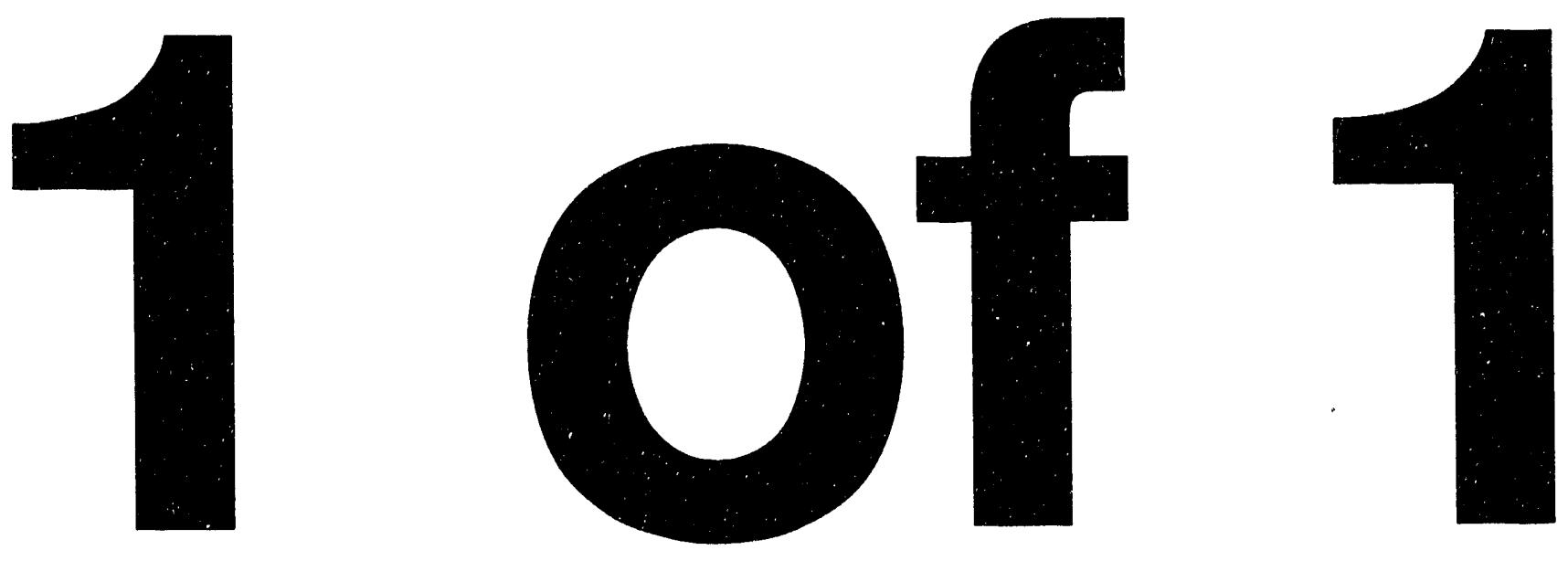
$\frac{12}{16.93932}$

UCRL-ID-114143

\section{Chemical Reaction Model for Oil and Gas Generation from Type I and Type II Kerogen}

Robert L. Braun

Alan K. Burnham

June 1993

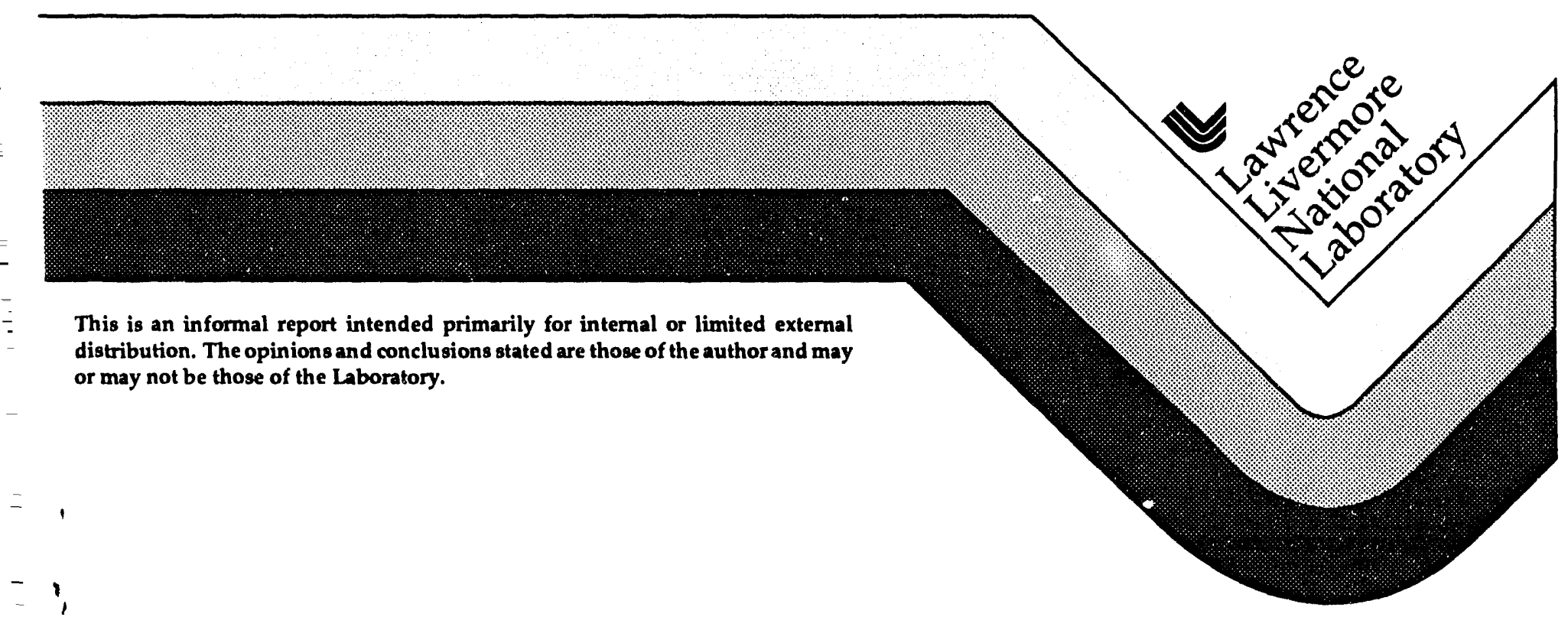




\section{DISCLAIMER}

This document was prepared as an account of work sponsored by an agency of the United States Government. Neither the United States Government nor the University of California nor any of their employees, makes any warranty, express or implied, or assumes any legal liability or responsibility for the accuracy, completeness, or usefulness of any information, apparatus, product, or process disclosed, or represents that its use would not infringe privately owned rights. Reference herein to any specific commercial products, process, or service by trade name, trademark, manufacturer, or otherwise, does not necessarily constitute or imply its endorsement, recommendation, or favoring by the United States Government or the University of California. The views and opinions of authors expressed herein do not necessarily state or reflect those of the United States Government or the University of California, and shall not be used for advertising or product endorsement purposes.

This report has been reproduced directly from the best available copy.

A vailable to DOE and DOE contractors from the Office of Scientific and Technical Information

P.O. Box 62, Oak Ridge, TN 37831

Prices a vailable from (615) 576.8401, FTS 626.8401

Available to the public from the

National Technical Information Service

US. Department of Commerce

5285 Port Royal Rd.,

Springfield, VA 22161 


\title{
Chemical Reaction Model for Oil and Gas Generation from Type I and Type II Kerogen
}

\author{
Robert L. Braun and Alan K. Burnham \\ Lawrence Livermore National Laboratory \\ Livermore, CA 94551
}

\begin{abstract}
A global model for the generation of oil and gas from petroleum source rocks is presented. The model consists of 13 chemical species and 10 reactions, including an alternatepathway mechanism for kerogen pyrolysis. Reaction rate parameters and stoichiometry coefficients determined from a variety of pyrolysis data are given for both type I and type II kerogen. Use of the chemical reaction model is illustrated for typical geologic conditions.
\end{abstract}

\section{INTRODUCTION}

A chemical model for the generation and destruction of hydrocarbons is an important part of petroleum-basin-modeling programs. We have formulated a number of chemical models of varying complexity that can be used for this purpose. Some of these have been briefly described (Braun and Bumham, 1992). The choice of which model to use depends on both the preference of the modeler and the detail of chemical compositional information desired for a particular purpose. The simplest model consists of 4 species and 2 reactions, which is the minimum needed to simulate oil generation and cracking. In the other simple models, we added more species and reactions, primarily to improve the reactions for oil cracking and residual kerogen pyrolysis. Those models are simple, generic ones for type I, II, and sometimes type III kerogen, developed from relatively limited sets of data.

In contrast, a very detailed chemical reaction model, consisting of 27 species and 19 reactions was developed specifically for the La Luna source rock (a carbonate-rich rock of the Maracaibo Basin, containing type II kerogen). The development and validation of that model, application to generic parameter studies of geological conditions, and comparisons of basin data with computer simulations are discussed by Burnham et al. (1992). While such a model can give very detailed predictions of product generation and composition, its development is very time consuming and, therefore, not always justifiable.

As a compromise, a model of intermediate complexity, consisting of 13 species and 10 reactions, is presented here. It incorporates the best features of the simpler models, but also contains an important feature of the complex model; namely, a bitumen intermediate and an altemate pathways mechanism for kerogen pyrolysis. In this report we discuss the calibration of this model for type I and type II kerogen using a variety of laboratory pyrolysis experiments. We also show the results given by this model for typical geologic conditions. Both the chemical reaction model development and the application studies were accomplished using PMOD, a 
flexible computer model of oil and gas generation, cracking, and expulsion (Braun and Bumham, 1992)

\section{FORMULATION OF MODEL}

Tables 1 and 2 show complete chemical reaction models for type 1 and type II kerogen, respectively. Empirical formulas of the chemical species are taken to be representative of generic type $\mathrm{I}$ and type II kerogens. The $\mathrm{CH}_{x}$ gas species includes $\mathrm{C}_{2}-\mathrm{C}_{4}$ hydrocarbon gases. The initial kerogen is partitioned into three kerogen species. Kerogen- 1 is the precursor of the earlygenerated carbon dioxide and water. Kerogen- 2 is the precursor of either a bitumen intermediate or other products, depending on the relative rates of the altemate pathways of reactions 2 and 3. Kerogen-3 is the precursor of only non-bitumen products. The model assumes that bitumen is merely soluble kerogen, with the same chemical formula and decomposition kinetics. Thus, kerogen-2, kerogen-3, and bitumen undergo identical pyrolysis reactions 3,4 , and 5 , respectively, to generate heavy oil, light oil, $\mathrm{CH}_{x}$ gas, methane, and three residual kerogen or coke species. The two oils and the $\mathrm{CH}_{x}$ gas pyrolyze to lighter fluids and residual solids by reactions 6,7 , and 8. Two of the residual solids are precursors of additional hydrocarbon gas, which is generated in reactions 9 and 10, while the third residual solid undergoes no further reaction. The Appendix briefly describes the model in terms of PMOD nomenclature (Table A1) and also gives the complete type I and type II chemistry files (Tables A2 and A.3).

Average kinetics for early generation of water and carbon dioxide from kerogen pyrolysis (reaction 1) were determined from a combination of pyrolysis-TQMS data (Reynolds et al., 1991; Braun et al., 1992) and hydrous pyrolysis data (Bumham et al., 1992). The data were not good enough to distinguish differences for type I and type II source rocks. For carbon dioxide, moreover, there is an incompatibility between the TQMS and hydrous pyrolysis measurements. The hydrous pyrolysis data indicate that most of the organic sarbon dioxide is generated very early in the reaction. In contrast, the TQMS data at $10{ }^{\circ} \mathrm{C} / \mathrm{min}$ indicate a broad background evolution, which may be due to inorganic carbonate decomposition, with a small organic peak at about $450{ }^{\circ} \mathrm{C}$. The carbon dioxide kinetics in this model were chosen to be compatible with the hydrous pyrolysis results. Decomposition of carbonate minerals has been ignored. Another discrepancy is that the measured water profile has additional peaks, which may be due to either organic or inorganic sources.

Average kinetics for bitumen generation (reaction 2) wise determined from analysis of hydrous pyrolysis data. For type I kerogen, data from Huizinga et al. (1988) were used. For type Il kerogen, data from Lewan (1985), Marzi (1989), Castelli et al. (1990), and Bumham et al. (1992) were used. Up to one half of the kerogen was allowed to go through the bitumen intermediate for type I kerogen, while only one third was allowed for type II kerogen. Average kinetics for oil generation (reactions 3, 4, and 5) were determined by fitting Pyromat data for type I and type Il source rocks (Braun et al., 1991), with corrections for the generation of hydrocarbon gas from residual kerogen pyrolysis described below. 
Average kinetics for cracking of heavy oil, light oil, and $\mathrm{CH}_{x}$ gas (reactions 6, 7, and 8) were determined from a review of the literature (Braun and Bumham, 1988). To enable a better fit of the oil product data from hydrous pyrolysis experiments, the original kinetics were slightly modified to incorporate a distribution of frequency factors for heavy oil and light oil cracking, with the oils from type II kerogen cracking somewhat faster than those from type I kerogen.

Average kinetics for generation of hydrocarbon gas from residual kerogen pyrulysis (reactions 9 and 10) were determined from gas evolution data from pyrolysis-TQMS experiments on various petroleum source rocks (Reynolds et al., 1991; Braun et al., 1992). These data were good enough to indicate differences between the type I and type Il source rocks for the residual kerogen gasification reactions.

Model calculations for production of $\mathrm{CH}_{4}, \mathrm{CH}_{x}$, and $\mathrm{CO}_{2}$ for an open-pyrolysis heating rate of $10^{\circ} \mathrm{C} / \mathrm{min}$ are shown in Figure 1. In these calculations, $\mathrm{CH}_{4}$ and $\mathrm{CH}_{x}$ are produced from primary kerogen, bitumen, and residual kerogen pyrolysis, while $\mathrm{CO}_{2}$ is produced only from the early kerogen pyrolysis reaction.

\section{COMPARISON OF MODEL CALCULATIONS WITH LABORATORY PYROLYSIS DATA}

\section{A. Type I source rocks}

Using the chemical reaction model in Table 1, a variety of pyrolysis experiments were simulated with PMOD. These include hydrous pyrolysis, thermal solution in tetralin, and conventional closed-system and open-system pyrolysis.

Simulation of hydrous pyrolysis can not be rigorously done with PMOD because of PMOD's inability to distinguish expelled and unexpelled fluids for closed-system pyrolysis. Our calculated bitumen is just one of the several chemical species in the model and is not operationally defined in terms of expellability or extractability as is done experimentally. We compare the measured bitumen extracted from the rock only with the total calculated bitumen species remaining, without any additional contribution from the calculated oil. We compare the measured oil expelled from the rock with the entire amount of calculated light and heavy oil product remaining. Despite these limitations of the model, Figure 2 shows excellent agreement of calculated bitumen and oil generation with the hydrous pyrolysis data of Huizinga et al. (1988). The onset of oil cracking is also in apparent agreement.

The thermal solution experiments of Leavitt et al. (1987) were also modeled with PMOD. To obtain the calculated yield, the residual organic solid (kerogen and coke) was subtracted from the initial kerogen. The measured and calculated fractional yields shown in Figure 3 are in good agreement over most of the temperature range, although the final measured yield indicates that less coke may be formed than prescribed by our chemical model.

Comparisons of PMOD calculations with the closed pyrolysis experiments of Evans and Felbeck (1983) are shown in Figure 4. At temperatures $\leq 350^{\circ} \mathrm{C}$ the measured yicld consists of a $\mathrm{C}_{15}$ organic extract with essentially no volatile organic liquids $\left(C_{6}\right.$ to $\left.C_{15}\right)$ or gaseous hydrocarbons $\left(C_{1}\right.$ to $\left.C_{5}\right)$. The large increase in measured $C_{15+}$ from 325 to $350{ }^{\circ} \mathrm{C}$ indicates 
a bitumen generation reaction with an activation energy substantially greater than the principal value of $50 \mathrm{kcal} / \mathrm{mol}$ used in the model. Since it is unlikely that the actual activation energy is that much greater, the validity of the measurement at $325{ }^{\circ} \mathrm{C}$ is in question. In the temperature rangc of 375 to $450{ }^{\circ} \mathrm{C}$, there is quite good agreement between the measured and calculated decrease in yield of the various fractions. The biggest discrepancy is that the measured amount of $C_{1}$ to $C_{5}$ is appreciably greater than the calculated amount. This suggests that the actual cracking reactions produce more light hydrocarbons and less residual solid than in the model.

Comparisons of PMOD calculations with the open system pyrolysis experiments of Miknis et al. (1985) are shown in Figure 5. It is apparent that, in contrast with the comparisons in the preceding paragraph, the measured rate of bitumen generation is much lower than the calculated rate. The total bitumen + oil + gas, however, is in good agreement at $394{ }^{\circ} \mathrm{C}$ and is approaching agreement for late times at $368^{\circ} \mathrm{C}$. The cracking reactions have little bearing on these comparisons, since most of the oil product is removed by the helium sweep before cracking can occur.

In summary, the model gives very good agreemment with bitumen generation data from hydrous pyrolysis experiments and thermal solution experiments, while bitumen comparisons for the other closed and open system isothermal pyrolysis experiments are somewhat contradictory. The generation of volatile oil and gaseous products is in good agreement with Pyromat data and pyrolysis-TQMS data, since that data was used in developing the model. Finally, with respect to oil cracking, the hydrous pyrolysis data for the decrease of oil at temperatures in excess of $350{ }^{\circ} \mathrm{C}$ agrees well with the model calculations. Although the closed pyrolysis data of Evans and Felbeck (1983) suggest improvements that could be made in the cracking model, the cracking model was derived from a broad review of the literature. Therefore, further modifications of the cracking model will be deferred until better knowledge of the kinetics and mechanism of oil cracking at relatively low temperatures and high pressures is obtained.

\section{B. Type II source rocks}

Using the chemical reaction model for type II source rocks in Table 2, three kinds of pyrolysis experiments were simulated with PMOD, in addition to the Pyromat and pyrolysisTQMS experiments that were used in developing the model.

Comparisors; of PMOD calculations with hydrous pyrolysis data for Phosphoria (Lewan, 1985), La Luna (Burnham et al. 1992), Posidonia (Marzi, 1989), and Monterey (Baskin and Peters, 1992) source rocks are shown in Figure 6. The same limitations on bitumen and oil comparisons that were discussed for type I source rocks apply here. The initial amount of oil in the four samples was taken to be zero. The initial amount of bitumen varied among the four samples, being largest for La Luna and Phosphoria, much less for Posidonia, and zero for Monterey. These differences were accounted for in the PMOD calculations. The calculated bitumen generation agrees very well for Phosphoria, while it is too fast for La Luna and Posidonia and too slow for Monterey. Considering the substantial variations in the measured values for both bitumen and oil, there is quite good overall agreement with the calculated values. This gives credence to 
the model reactions for kerogen and bitumen pyrolysis. The calculated decrease in oil at high temperature matches the measured decrease quite well for the three source rocks having hydrous pyrolysis data above $340^{\circ} \mathrm{C}$, supporting the validity of the oil cracking kinetics in the model.

A more thorough evaluation of the model was obtained by comparison with the closed pyrolysis experiments of Monin et al. (1990). Little attempt was made to optimize the model with these data, because the model was derived primarily from other experiments. The measured hydrogen index decreases faster than calculated, suggesting perhaps that the early soluble organic matter has more hydrogen content than the remaining kerogen. The temperatures for the calculated creation and destruction of bitumen correlate well with the experimental asphaltene species, although the calculated amount is too high. Other species concentrations calculated by the model agree fairly well with the experimental data.

Comparisons of PMOD calculations with the open system pyrolysis experiments of Miknis et al. (1987) are shown in Figure 8. Compared with the results for type 1 kerogen (Figure 5), the calculated bitumen production for type 11 kerogen is in better agreement with the measured production, particularly at $400{ }^{\circ} \mathrm{C}$. The total bitumen + oil + gas is again in good agreement at $400{ }^{\circ} \mathrm{C}$ and is approaching agreement for late times at $375^{\circ} \mathrm{C}$.

\section{APPLICATION OF MODEL TO GEOLOGIC CONDITIONS}

In Figures 9 and 10 the two generic chemistry models were used along with the pressuredriven expulsion model in PMOD to predict the natural maturation results for $8 \mathrm{wt} \%$ TOC at a heating rate of $4{ }^{\circ} \mathrm{C} / \mathrm{My}$ and a geothermal gradient of $25{ }^{\circ} \mathrm{C} / \mathrm{km}$. These calculations assumed an expellability fartor of 0.1 for bitumen. The porosity model is that described by Braun and Burnham (1992), with $K_{\epsilon}=4.5 \times 10^{-8}$. Table A4 of the Appendix gives other physical/chemical parameters used in the calculations.

Figure 9 shows that, for a given TOC, a higher pore poressure is obtained for type I source rocks. This, in tum, causes a higher porosity to be maintained during the principal period of conversion of solid organic matter to fluids. If no increase in porosity had been allowed, the pore pressure would have been substantially higher. Note that the Tmax shown in Figure 9 is the kinetics Tmax; the Rock-Eval Tmax would be approximately $35^{\circ} \mathrm{C}$ lower. Figure 10 illustrates differences in oil and gas yields, oil composition, and API gravity for type I and II source rocks.

\section{ACKNOWLEDGEMENTS}

This work was performed under the auspices of the U.S. Department of Energy by the Lawrence Livermore National Laboratory under Contract W-7405-Eng-48. It was supported by the USDOE Office of Basic Energy Sciences and group of industrial sponsors. 


\section{REFERENCES}

Baskin D. K., Peters K. E. (1992) Early generation characteristics of a sulfur-rich Monterey kerogen. AAPG Bul. 76, 1-13.

Braun R. L., Burnham A. K. (1988) Thermal cracking of hydrocarbons. Lawrence Livermore Nat. Lab. Rept. UCID-21507, Avail. NTIS, Springfield, VA.

Braun R. L., Burnham A. K., Reynolds J. G., Clarkson J. E. (1991) Pyrolysis kinetics for lacustrine and marine source rocks by programmed micropyrolysis. Energy \& Fuels 5, 192-204.

Braun R. L., Burnham A. K. (1992) PMOD: a flexible model of oil and gas generation, cracking, and expulsion. Org. Geochem. 19, 161-172.

Braun R. L., Burnham A. K., Reynolds, J. G. (1992) Oil and gas evolution kinetics for oil shale and petroleum source rocks determined from pyrolysis-TQMS data at two heating rates. Energy \& Fuels 6, 468-474.

Bumham A. K., Braun R. L., Sweeney J. J., Reynolds J. G., Vallejos C., and Talukdar S. (1992) Kinetic modeling of petroleum formation in the Maracaibo Basin: Final report. U.S. Dept. Energy Rept. DOE/BC/92001051.

Evans R. J. Felbeck G. T. Jr. (1983) High temperature simulation of petroleum formation-I. The pyrolysis of Green River shale. Org. Geochem. 4, 135-144.

Huizinga B. J., Aizenshtat Z. A., Peters, K. E. (1988) Programmed pyrolysis-gas chromatography of artificially matured Green River kerogen. Energy \& Fuels 2, 74-81.

Leavitt D. R., Tyler A. L., Kafesjian A. S. (1987) Kerogen decomposition kinetics of selected Green River and Eastern U. S. oil shales from thermal solution experiments. Energy \& Fuels 1, 520-525.

Lewan M. D. (1985) Evaluation of petroleum generation by hydrous pyrolysis experimentation. Phil. Trans. R. Soc. Lond. A 315, 123-134.

Miknis F. P., Tumer T. F., Berdan G. L., Conn P. J. (1985) Isothermal decomposition of Colorado oil shale. Report DOE/FE/60177-2288; Westem Research Institute; Laramie, WY.

Miknis F. P., Turner T. F., Berdan G. L., Conn P. J. (1987) Formation of soluble products from thermal decomposition of Colorado and Kentucky oil shales. Energy \& Fuels 1, 477-483.

Marzi R. (1989) Kinetik und quantitative Analyse der Isomerisierung und Aromatisierung von fossilen Steroidkohlenwasserstoffen im Experiment und in natürlichen Probensequenzen. Berichte der Kernforschungsanlage Jülich - Nr. 2264, Zentralbibliothek der Kernforschungsanlage Jülich GmbH, Germany.

Monin J. C., Connarı J., Oudin J. L., Durand B. (1990) Quantitative and qualitative experimental approach of oil and gas generation: Application to the North Sea source rocks. Org. Geochem. 16, 133-142.

Reynolds J. G., Crawford R. W., Bumham A. K. (1991) Analysis of oil shale and petroleum source rock pyrolysis by triple quadrupole mass spectrometry: comparisons of gas evolution at the heating rate of $10^{\circ} \mathrm{C} / \mathrm{min}$. Energy \& Fuels 5, 507-523. 
Table 1. Pyrolysis model for type I kerogen with mass stoichiometry factors and kinetics $\left[A\left(\mathrm{~s}^{-1}\right), E(\mathrm{kcal} / \mathrm{mol})\right.$, and $f$ (distribution fraction)]

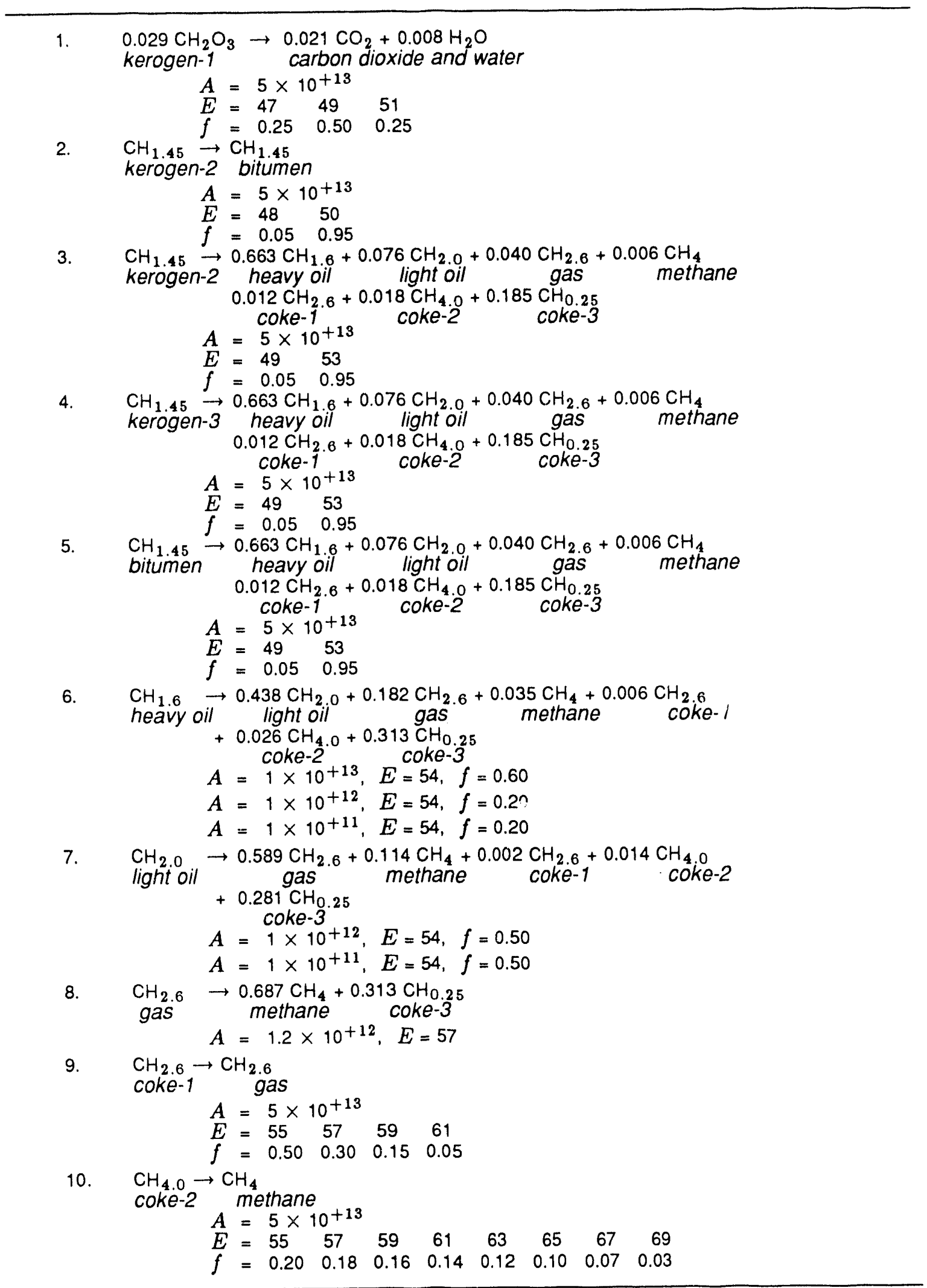


Table 2. Pyrolysis model for type II kerogen with mass stoichiometry factors and kinetics $\left[A\left(\mathrm{~s}^{-1}\right), E(\mathrm{kcal} / \mathrm{mol})\right.$, and $f$ (distribution fraction) $]$

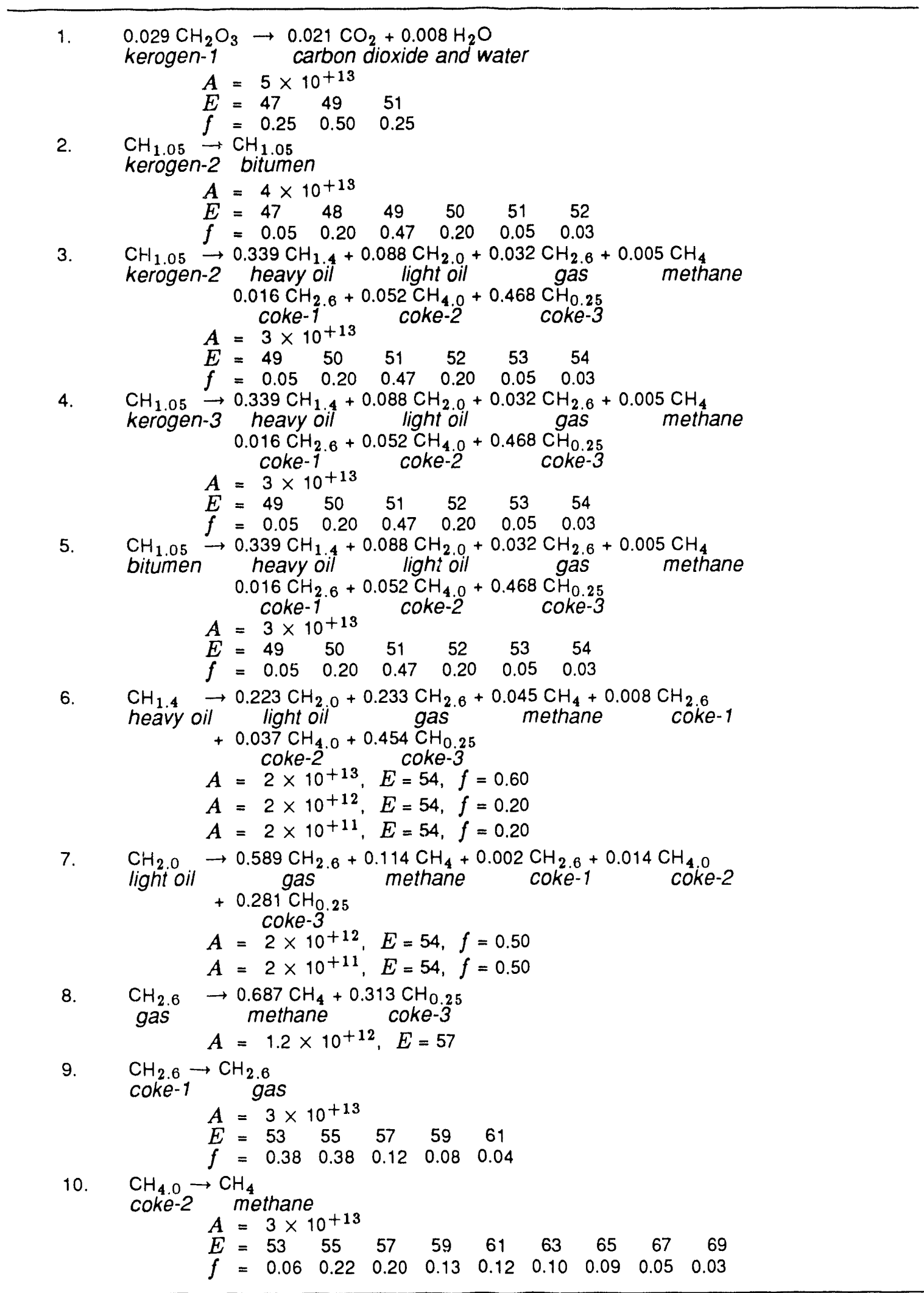




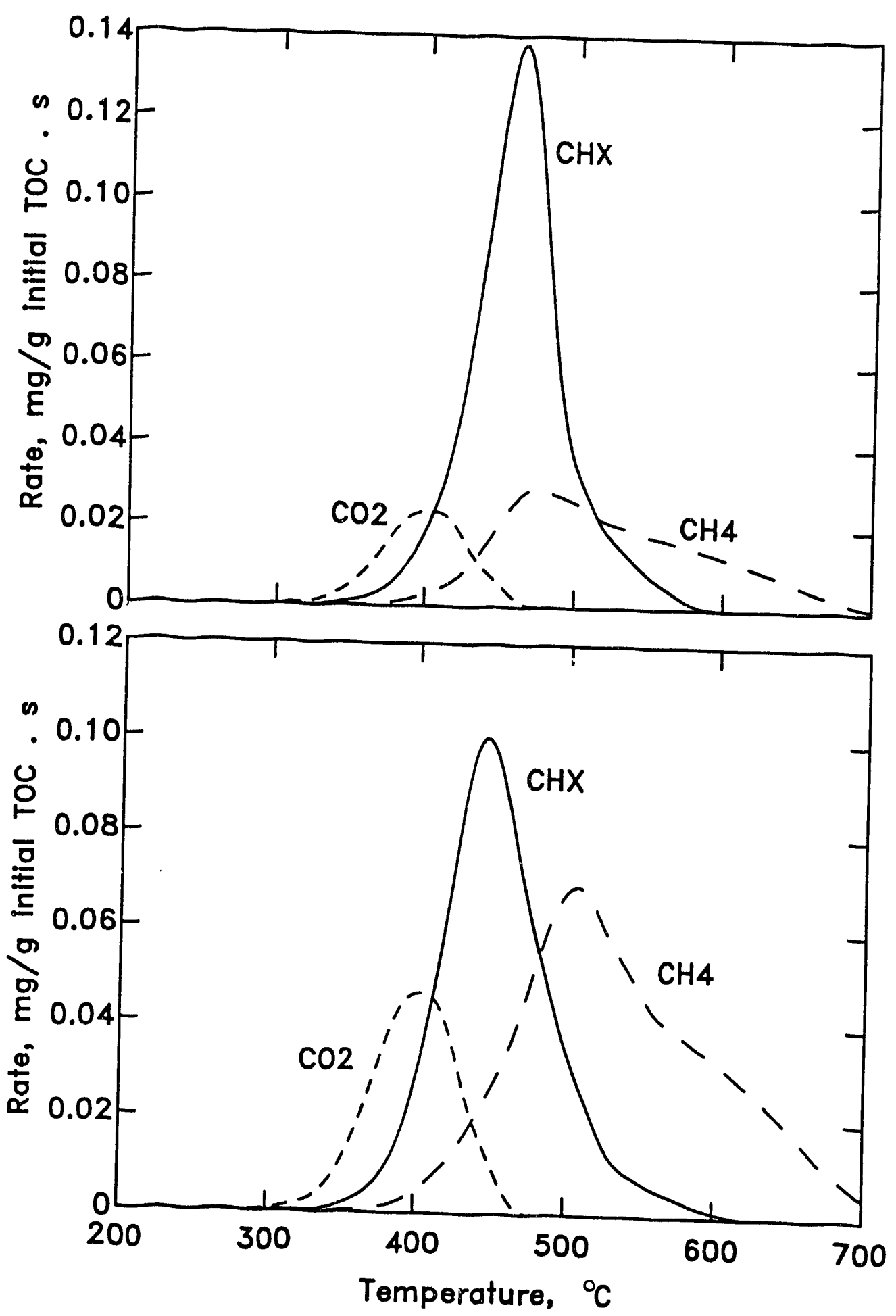

Figure 1. Rate profiles calculated with PMOD for open pyrolysis of type I and type II source rocks at a heating rate of $10^{\circ} \mathrm{C} / \mathrm{min}$. 


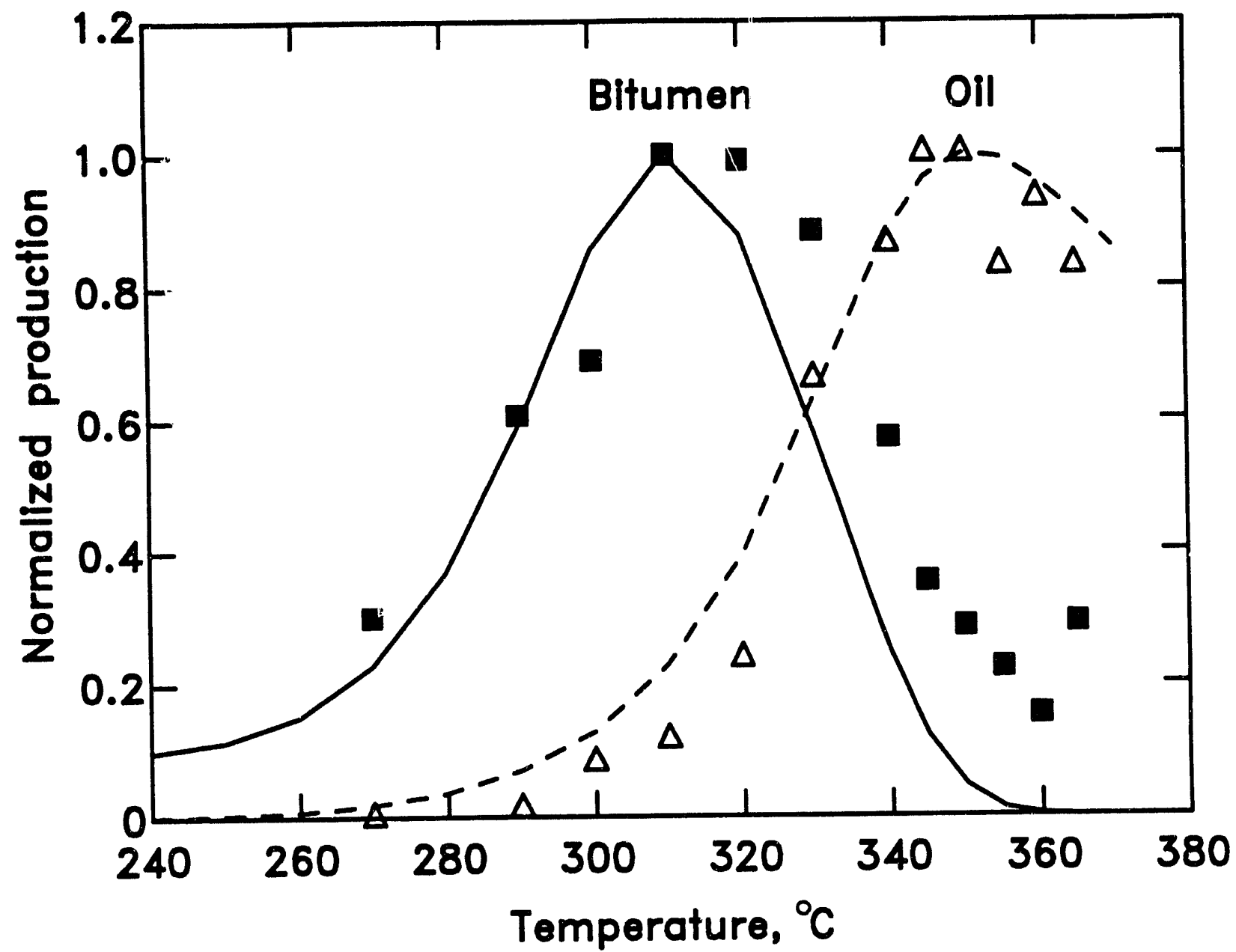

Figure 2. Comparison of hydrous pyrolysis data for Green River shale (Huizinga et al., 1988) with PMOD calculations using generic chemistry model for type I source rock. A heating time of $72 \mathrm{~h}$ at the indicated temperature was used. 


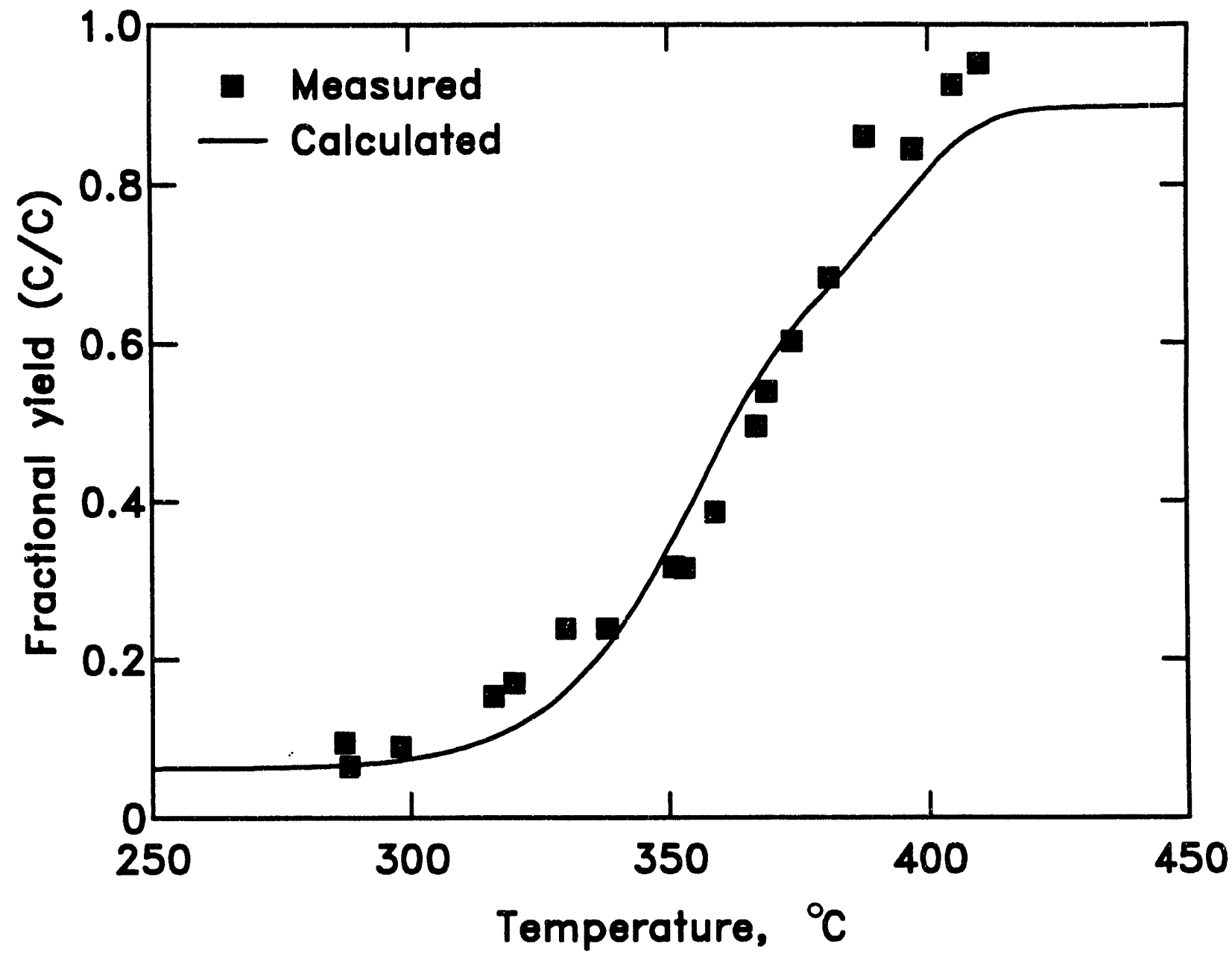

Figure 3. Comparison of thermal solution yield for Gresn River shale (Leavitt et al., 1987) with PMOD calculations using generic chemistry model for type I source rock. A heating rate of $0.2^{\circ} \mathrm{C} / \mathrm{min}$ was used. 


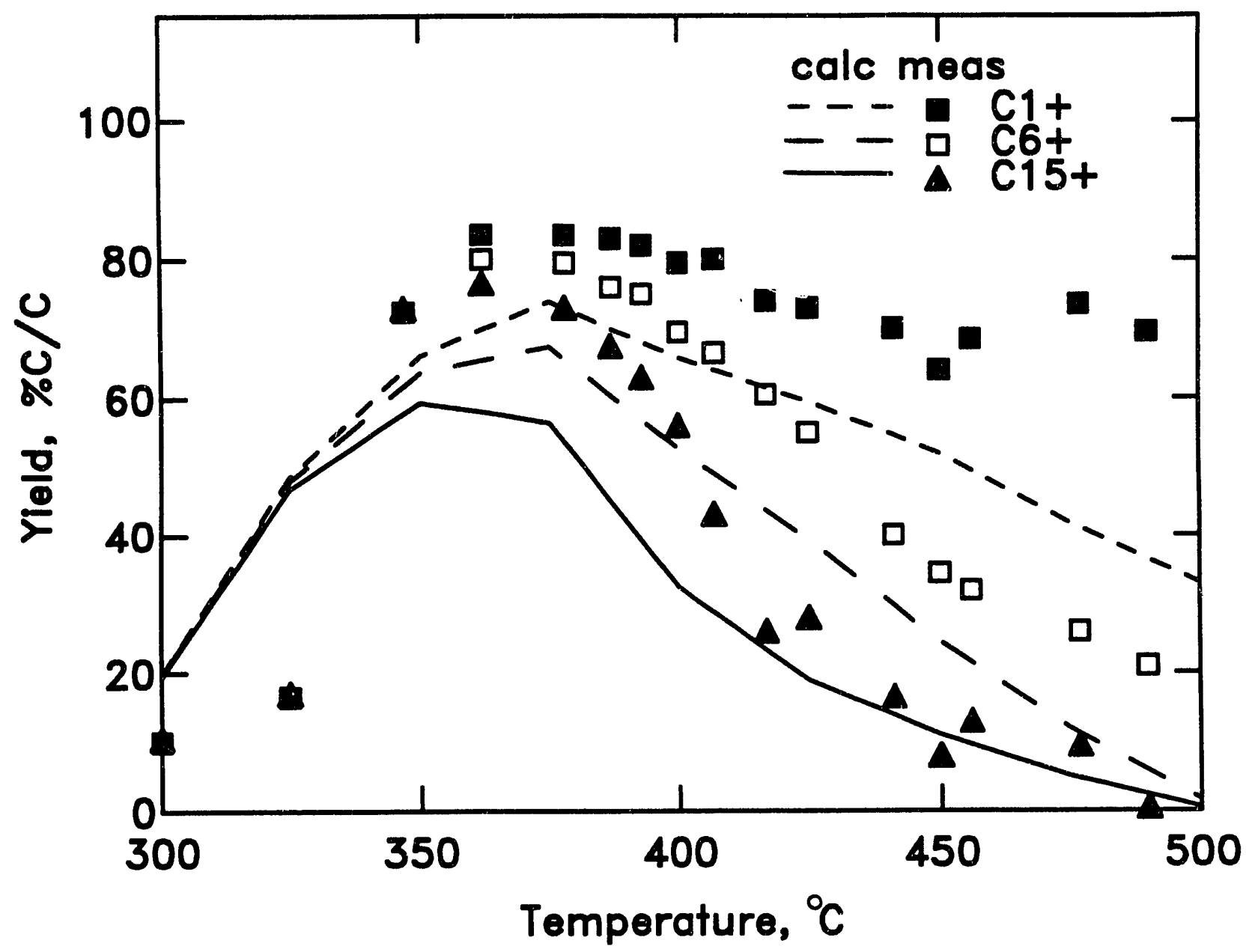

Figure 4. Comparison of closed pyrolysis data for Green River shale (Evans and Felbeck, 1983) with PMOD calculations using generic chemistry model for type I source rock. A heating time of $16 \mathrm{~h}$ at the indicated temperature was used. 

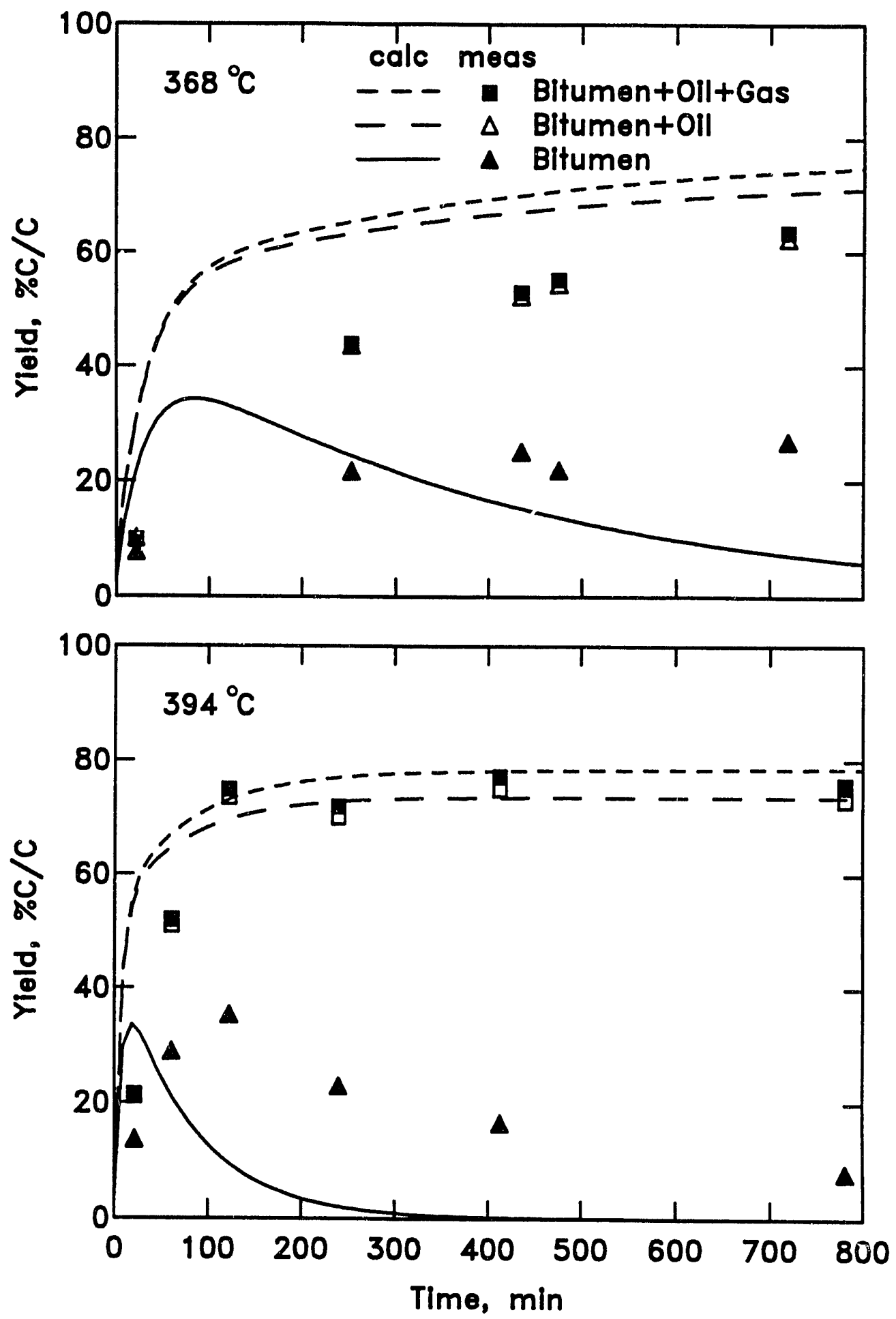

Figure 5. Comparison of open pyrolysis data for Green River shale (Miknis et al., 1985) with PMOD calculations using generic chemistry model for type I source rock. 

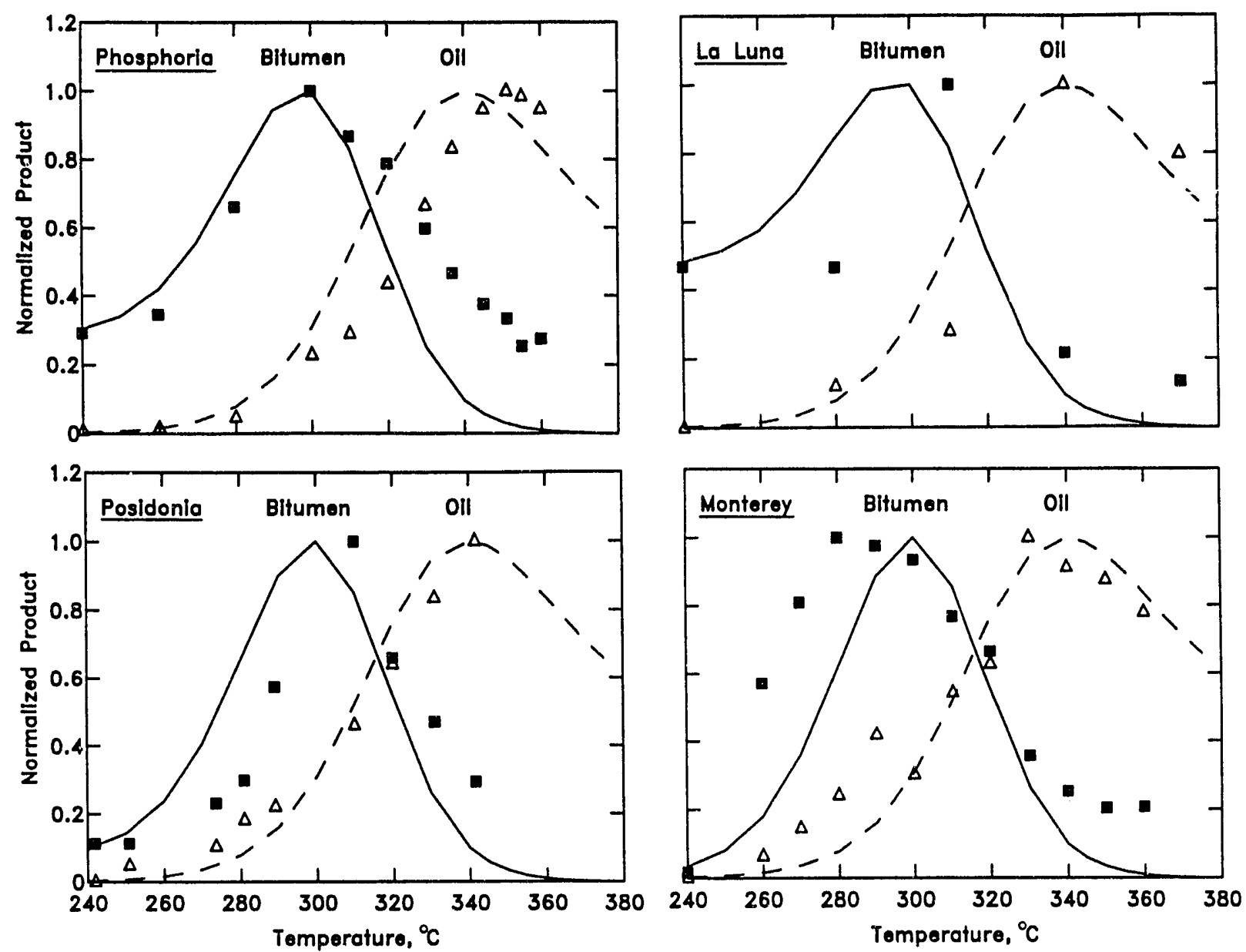

Figure 6. Comparison of hydrous pyrolysis data for Phosphoria (Lewan, 1985), La Luna (Burnham et al. 1992), Posidonia (Marzi, 1989), and Monterey (Baskin and Peters, 1992) source rocks with PMOD calculations using generic chemistry model for type II source rock. A heating time of $72 \mathrm{~h}$ at the indicated temperature was used. 


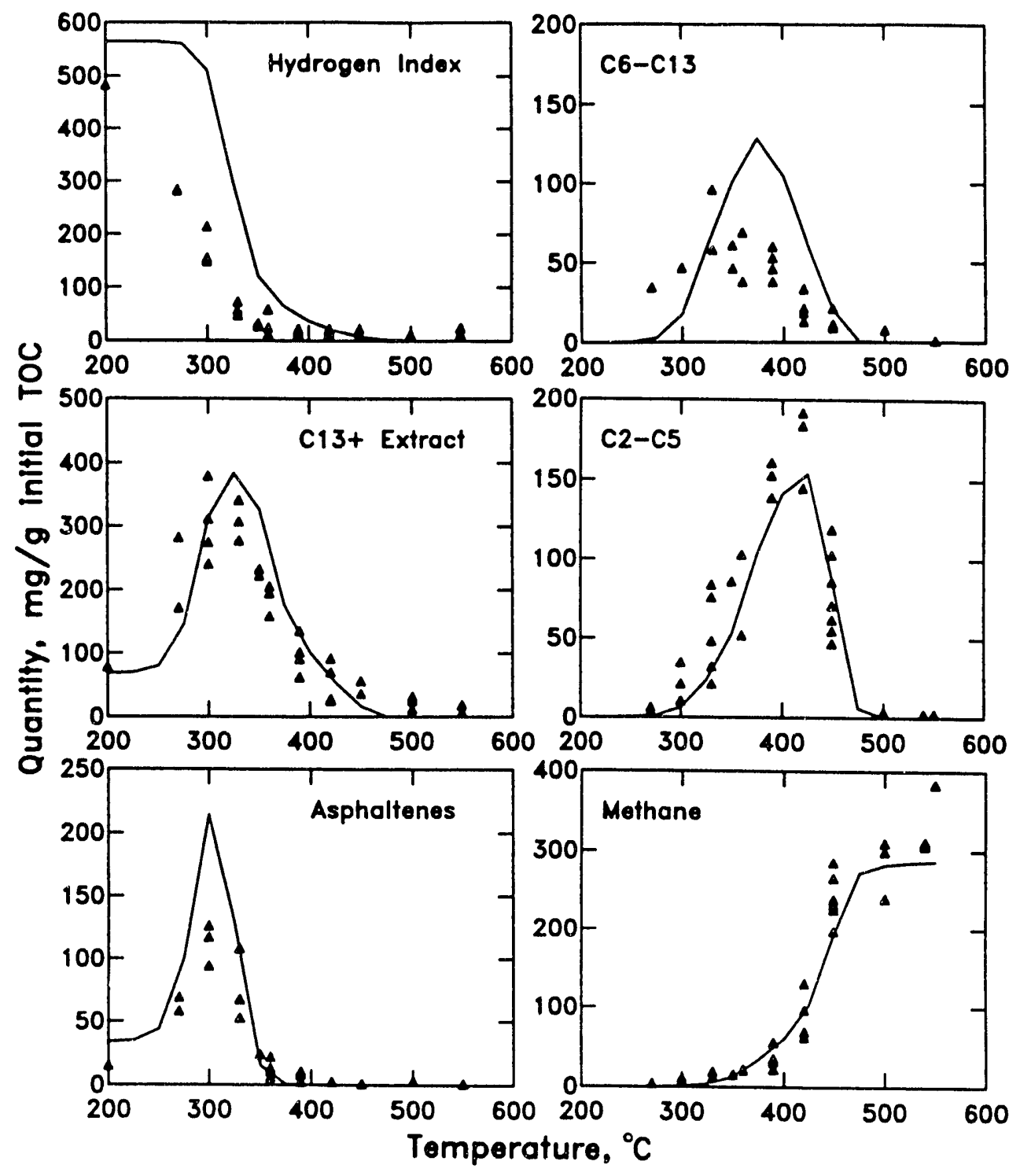

Figure 7. Comparison of closed pyrolysis data for Kimmeridge shale (Monin et al., 1990) with PMOD calculations using generic chemistry model for type II source rock. A heating time of $45 \mathrm{~h}$ at the indicated temperature was used. 

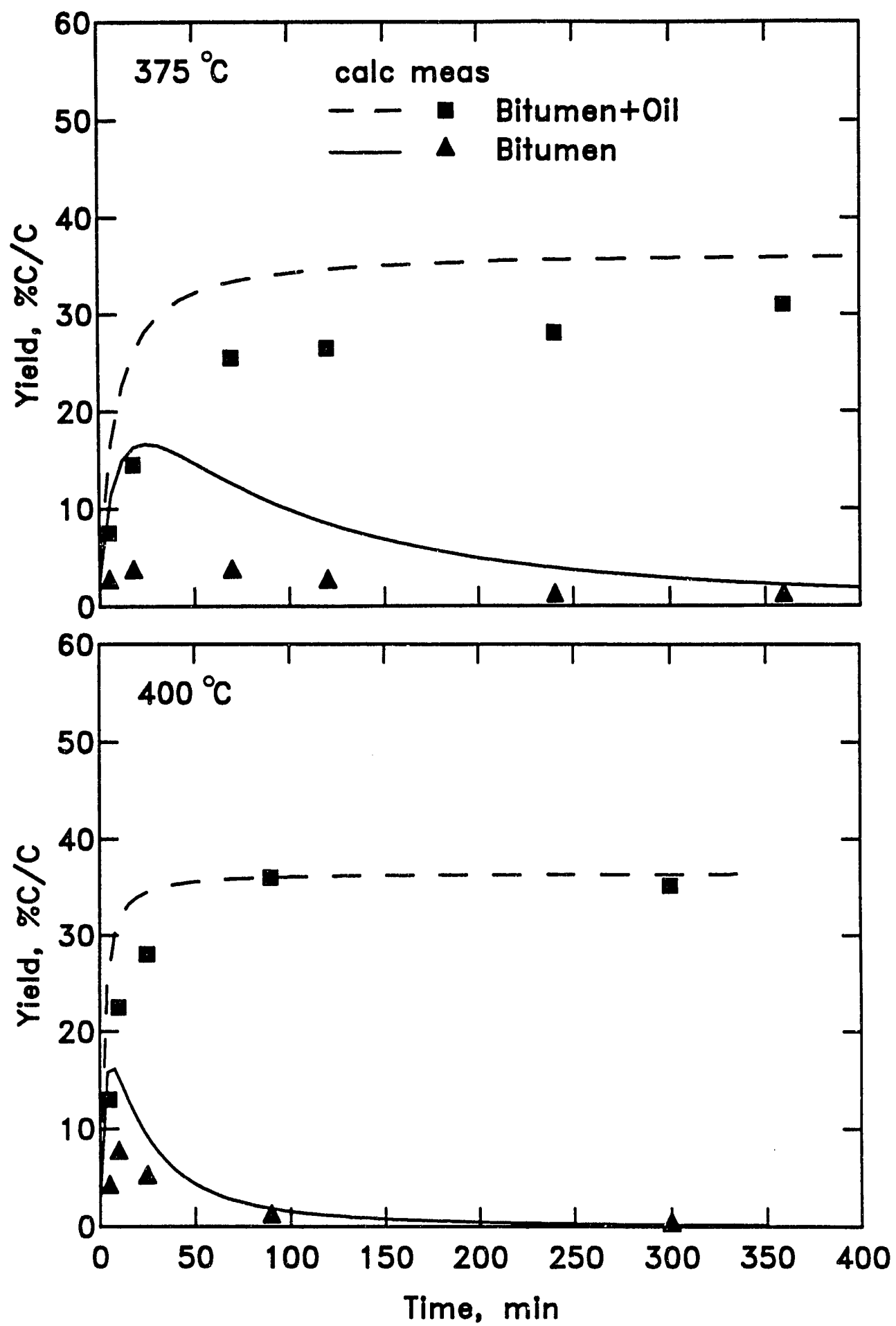

Figure 8. Comparison of open pyrolysis data for Kentucky shale (Miknis et al., 1987) with PMOD calculations using generic chemistry model for type II source rock. 

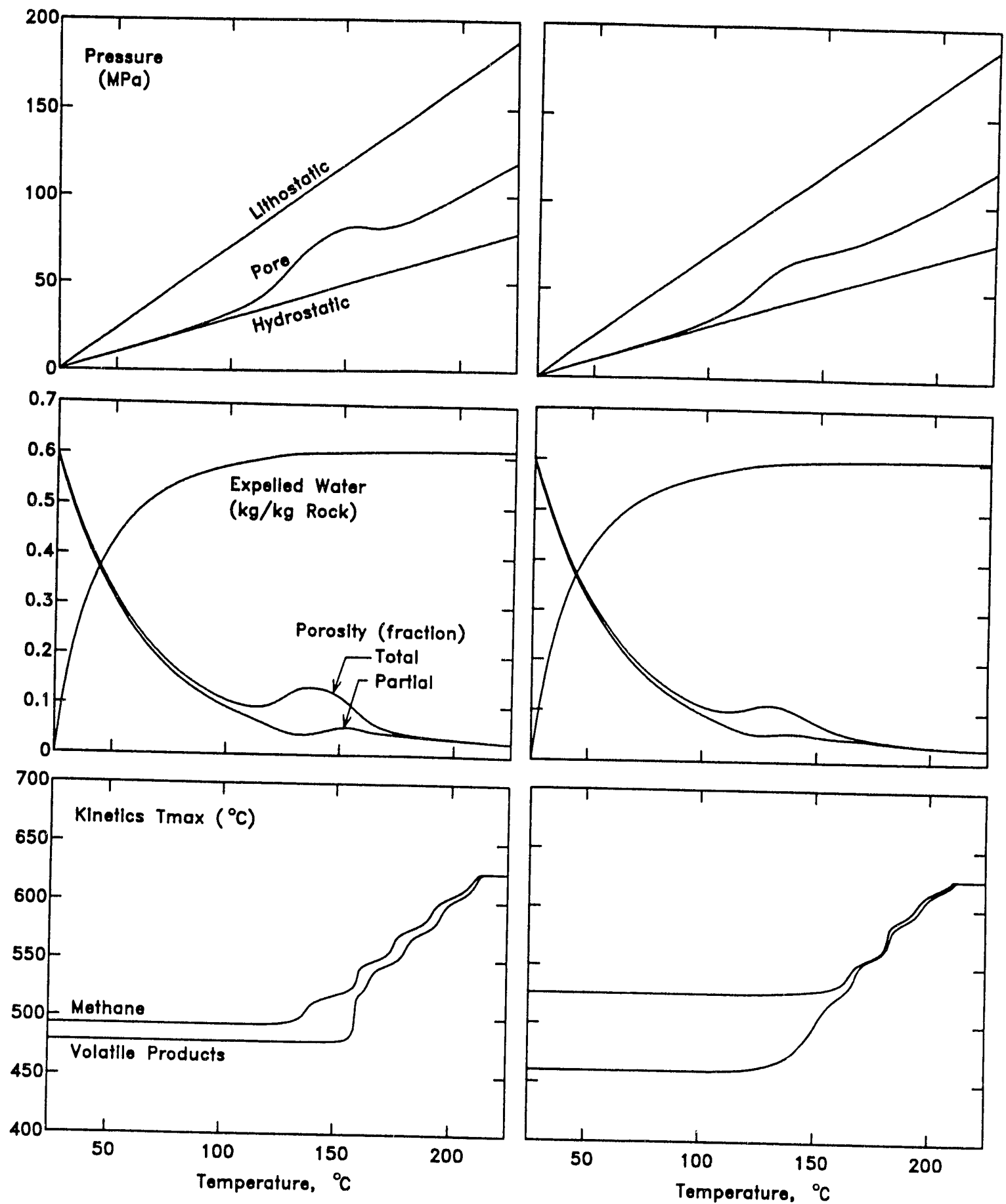

Figure 9. Comparison of predicted maturation results for type I (left) and type II (right) source rocks, using pressure-driven expulsion model, $8 \mathrm{wt} \%$ TOC, $4{ }^{\circ} \mathrm{C} / \mathrm{My}$, and $25^{\circ} \mathrm{C} / \mathrm{km}$. Partial porosity is that not filled with heavy oil and bitumen. 

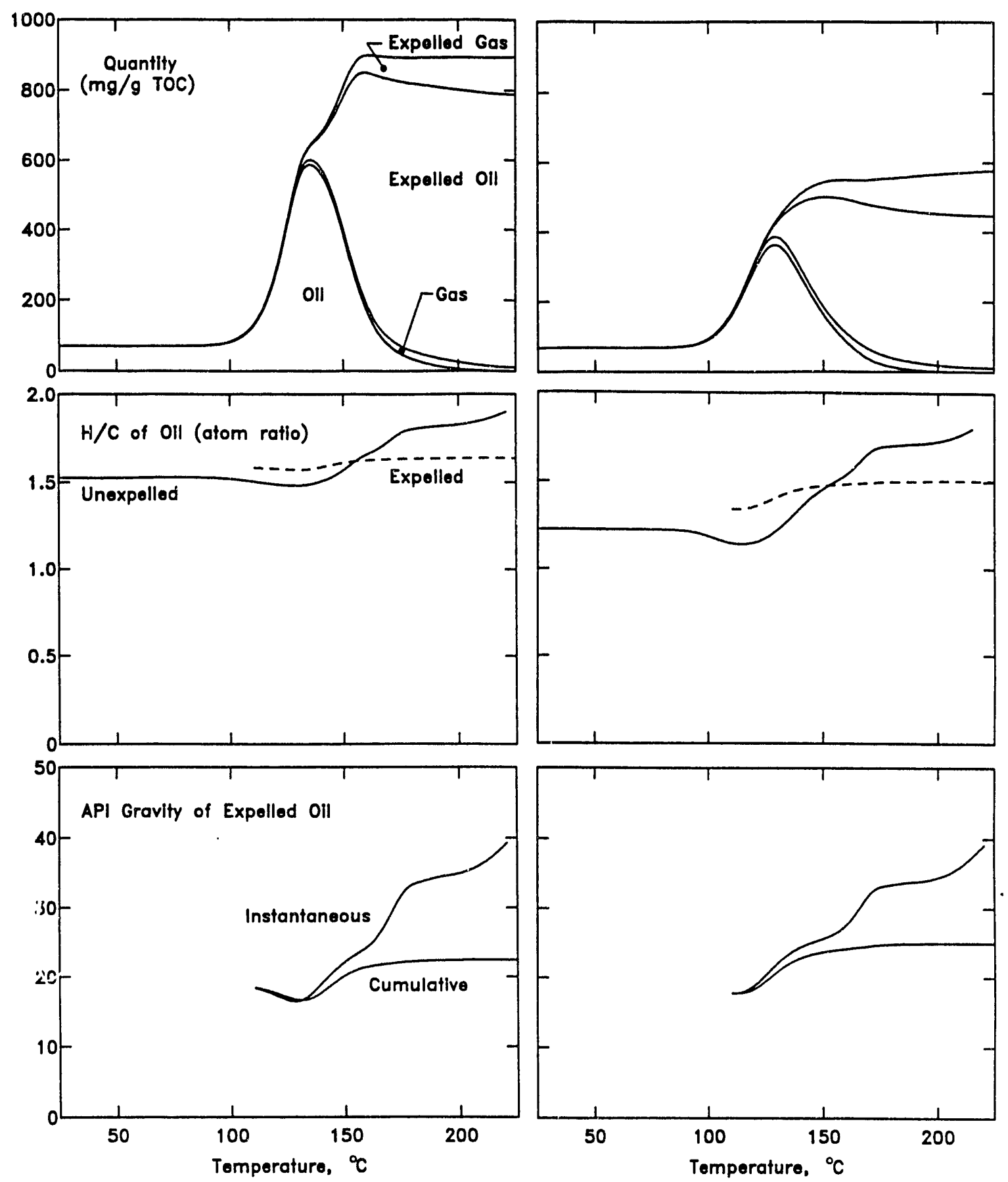

Figure 10. Comparison of predicted maturation results for type I (left) and type II (right) source rocks, using pressure-driven expulsion model, $8 \mathrm{wt} \%$ TOC, $4{ }^{\circ} \mathrm{C} / \mathrm{My}$, and $25^{\circ} \mathrm{C} / \mathrm{km}$. Oil denotes the sum of oil and bitumen. Curves in the top graphs are plotted cumulatively in the order unexpelled oil, gas, expelled oil, and expelled gas. 


\section{APPENDIX \\ CHEMICAL REACTION MODEL IN TERMS OF PMOD NOMENCLA'TURE}

The structure of this chemical reaction model (known as Model H to PMOD users) is shown in Table A1. The complete chemistry files (H1.KEM and H2.KEM) for type I and type II kerogen are shown in Tables A2 and A3, respectively. The empirical formulas for the chemical species shown in those tables are taken to be representative of generic type I and type II kerogens. The initial kerogen is partitioned into 3 species. KER1 is the precursor of the early-generated $\mathrm{CO} 2$ and $\mathrm{H} 2 \mathrm{O}$. KER2 is the precursor of either a bitumen intermediate $\mathrm{HO} 3$ ) or other products, depending on the relative rates of the altemate pathways of reactions 2 and 3. KER3 is the precursor of only non-bitumen products. The model assumes that bitumen is merely soluble kerogen, with the same chemical formula and decomposition kinetics. Thus, KER2, KER3, and HO3 undergo identical reactions 3,4 , and 5, respectively, to generate heavy oil (HO1), light oil (LO1), hydrocarbon gas ( $\mathrm{CHX}$ ), methane $(\mathrm{CH} 4)$, and three residual kerogen species (KER4, KER5, and KER6). The two oils and the hydrocarbon gas pyrolyze to lighter fluids and residual solids by reactions 6,7 , and 8 . The residual KER4 and KER5 are precursors of $\mathrm{CHX}$ and $\mathrm{CH} 4$, respectively, as shown in reactions 9 and 10 , while the residual KER6 undergoes no further reaction.

In Tables A2 and A3 nominal values are given for the initial bitumen ( $\mathrm{HO} 3$ ) and heavy oil (HO1) in the data section labeled "Relative amount of inital TOC in species" just after definition of the empirical formulas. These values should be modified to use the actual initial, relative amounts of bitumen and oil for the specific source rock that is modeled.

The PMOD physical/chemical properties file used in the pressure-driven expulsion calculations shown in Figures 9 and 10 is given in Table A4. Note that the TOC is given in this file.

Table A1. Chemical reaction scheme for Model $\mathrm{H}$.

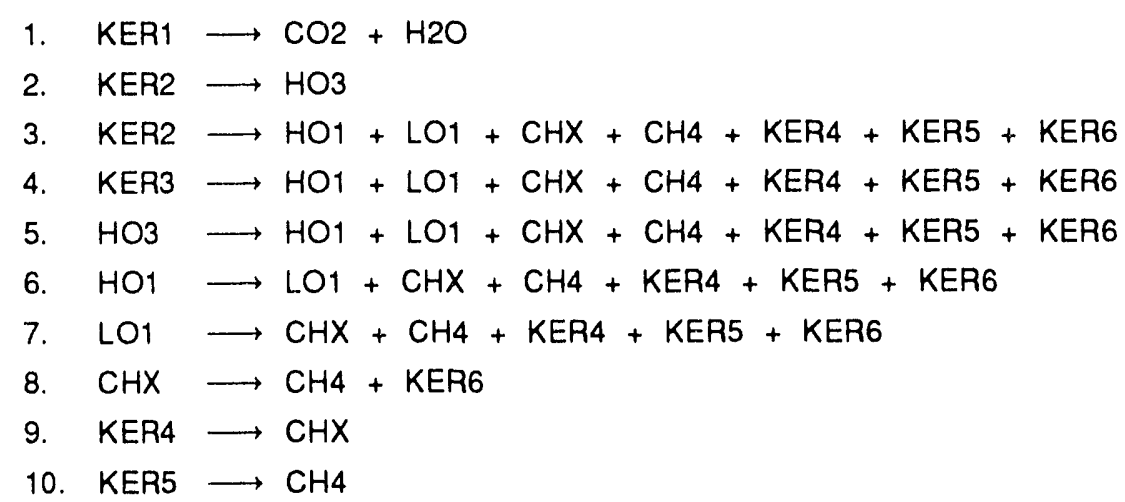


Table A2. Model $\mathbf{H}$ chemistry file for Type I kerogen

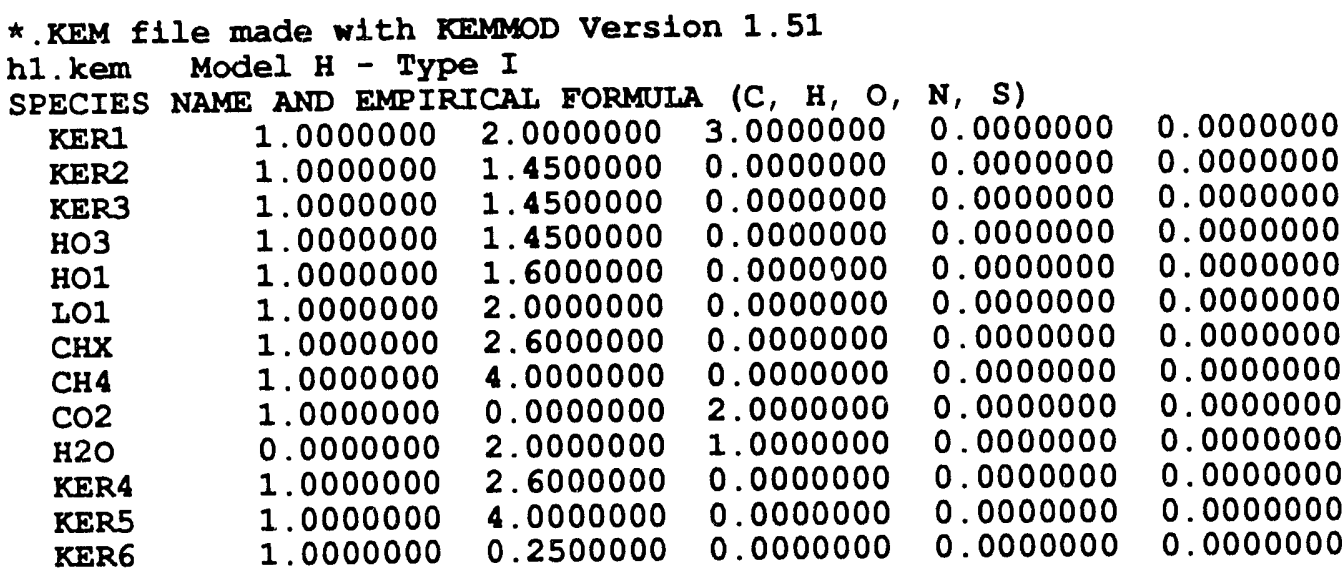

REIATIVE AMOUNT OF INITIAI TOC IN SPECIES

$\begin{array}{ll}\text { KER1 } & 0.0060000 \\ \text { KER2 } & 1.0000000 \\ \text { KER3 } & 1.0000000 \\ \text { HO3 } & 0.0670000 \\ \text { HO1 } & 0.0670000\end{array}$

REACTION 1

1 REACTANTS

KERI

2 PRODUCTS

$\mathrm{CO} 2$ H2O

3 ENERGIES

2.50000E-01 5.00000E+13 4.70000E+04

5. $00000 \mathrm{E}-01 \quad 5.00000 \mathrm{E}+13 \quad 4.90000 \mathrm{E}+04$

$2.50000 \mathrm{E}-01 \quad 5.00000 \mathrm{E}+13 \quad 5.10000 \mathrm{E}+04$

FORMUIA STOICHIOMETRY COEFEICIENTS

$-1.00000 \mathrm{E}+00 \quad 1.00000 \mathrm{E}+00 \quad 1.00000 \mathrm{E}+00$

MASS STOICHIOMETRY COEFFICIENTS

$\begin{array}{lll}-1.00000 \mathrm{E}+00 & 7.09549 \mathrm{E}-01 & 2.90451 \mathrm{E}-01\end{array}$

REACTION 2

1 REACTANTS

KER2

1 PRODUCTS

HO3

2 ENERGIES

5.00000E-02 5.00000E+13 4.80000E+04

$9.50000 \mathrm{E}-01 \quad 5.00000 \mathrm{E}+13 \quad 5.00000 \mathrm{E}+04$

FORMULA STOICHIOMETRY COEFEICIENTS

$-1.00000 \mathrm{E}+00 \quad 1.00000 \mathrm{E}+00$

MASS STOICHIOMETRY COEFFICIENTS

$-1.00000 \mathrm{E}+00 \quad 1.00000 \mathrm{E}+00$

REACTION 3

1 REACTANTS

KER2

7 PRODUCTS

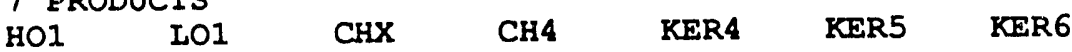

2 ENERGIES

5.00000E-02 5.00000E+13 4.90000E+04

$9.50000 \mathrm{E}-01 \quad 5.00000 \mathrm{E}+13 \quad 5.30000 \mathrm{E}+04$

STOICHIOMETRY CONSTRAINTS ARE FORMULA RATIOS FOR ALL REACTIONS

9.00000E-01 HO/TOTAL OII

5.00000E-02 CHX/TOTAL OIX

1.25000E-01 CH4/(CHX+CH4+H2)

1. $40000 \mathrm{E}+00$ KER5/KER4

1. $90000 \mathrm{E}+01$ KER6/KER4

FORMULA STOICHIOMETRY COEFEICIENTS 


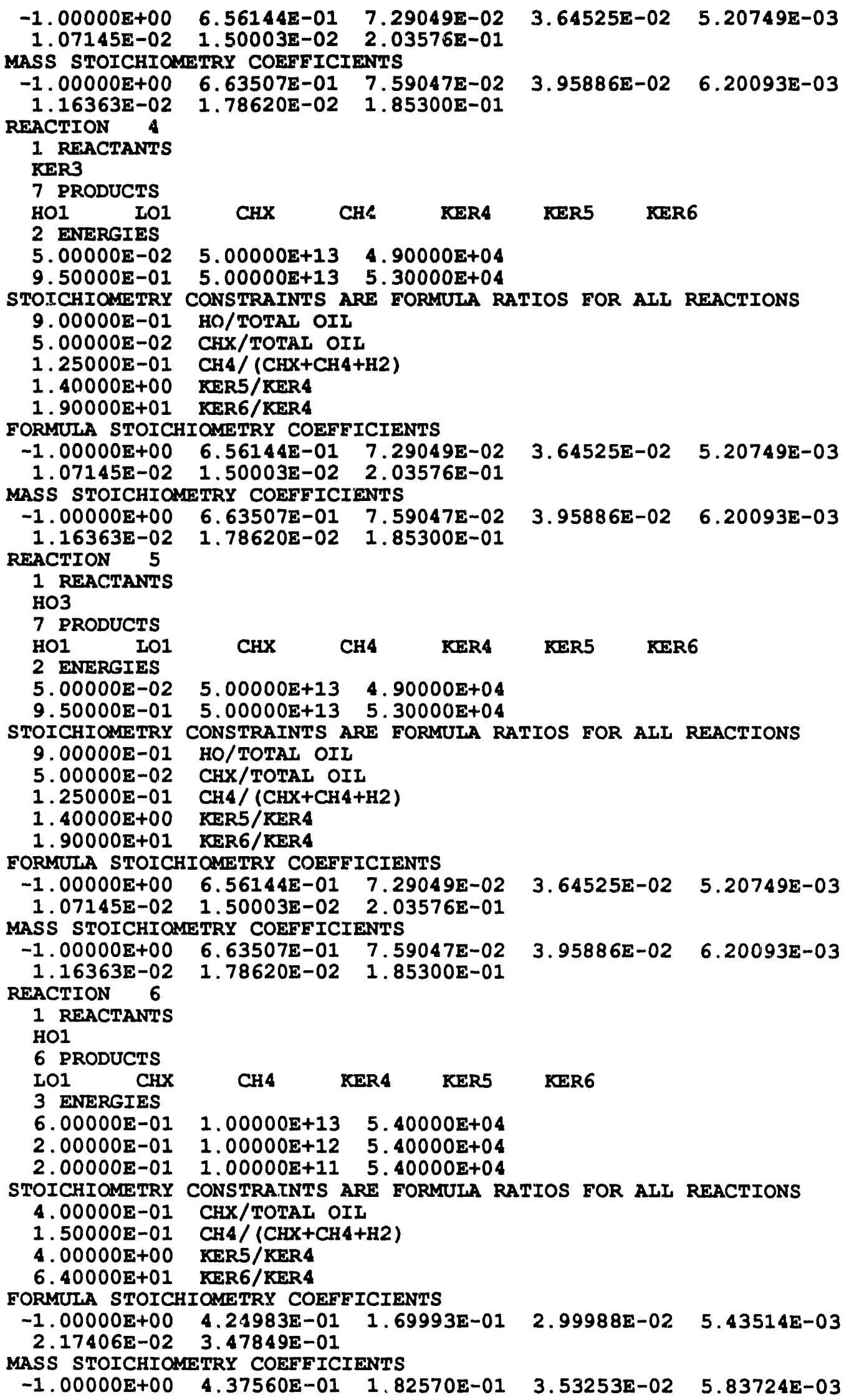

$3.64525 \mathrm{E}-02 \quad 5.20749 \mathrm{E}-03$

$3.95886 \mathrm{E}-02 \quad 6.20093 \mathrm{E}-03$

3. 64525E-02 5.20749E-03

$3.95886 E-02 \quad 6.20093 E-03$

1. $85300 \mathrm{E}-01$

$\begin{array}{ll}5.00000 \mathrm{E}+13 & 4.90000 \mathrm{E}+04 \\ 5.00000 \mathrm{E}+13 & 5.30000 \mathrm{E}+04\end{array}$

CONSTRAINTS ARE FORMUIA RATIOS FOR ALI REACTIONS

HO/TOTAL OII

CHX/TOTAL OIL

CHA (CHX+CH4+H2)

$63507 \mathrm{E}-01$ 


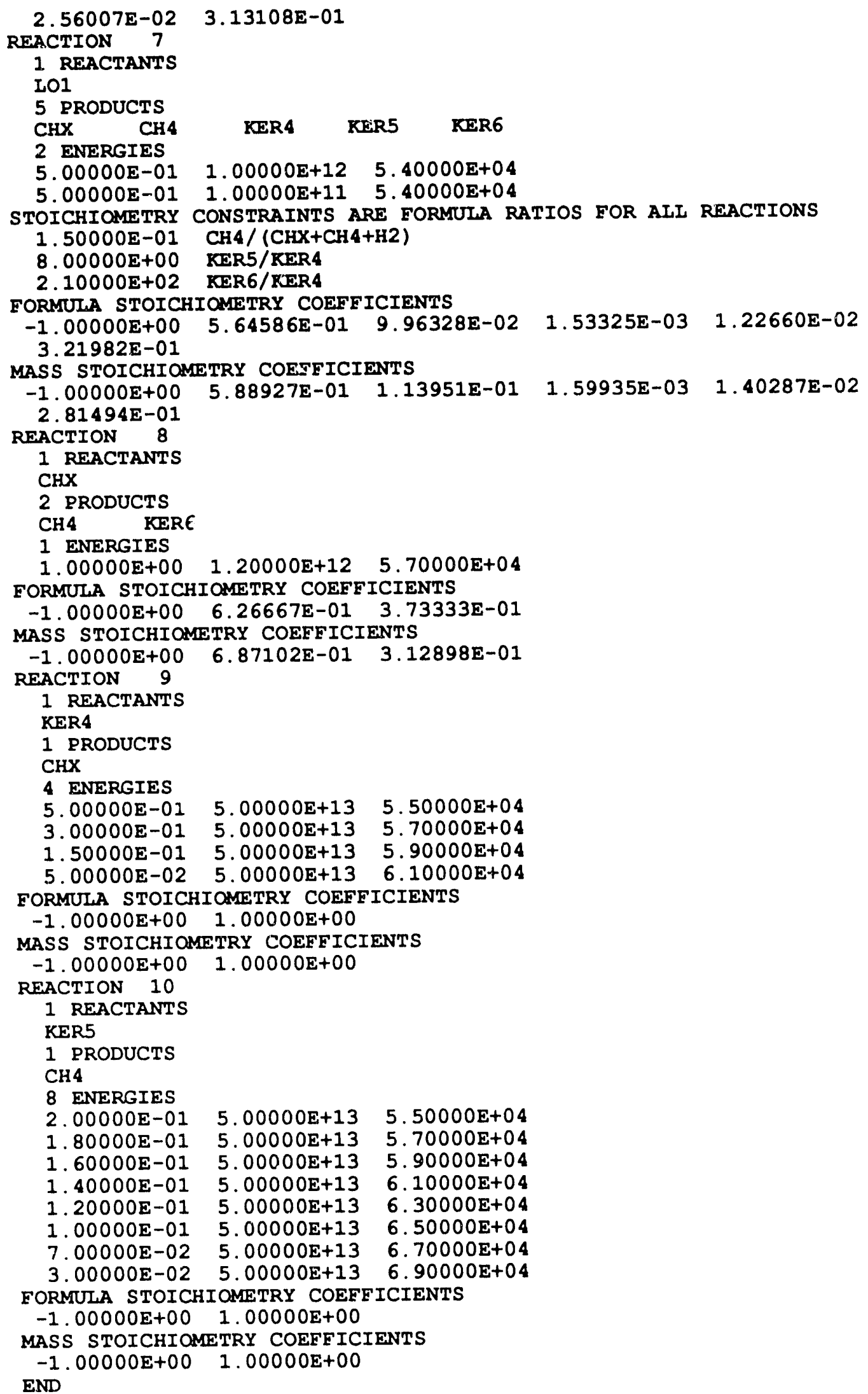


Table A3. Model $\mathbf{H}$ chemistry file for Type II kerogen

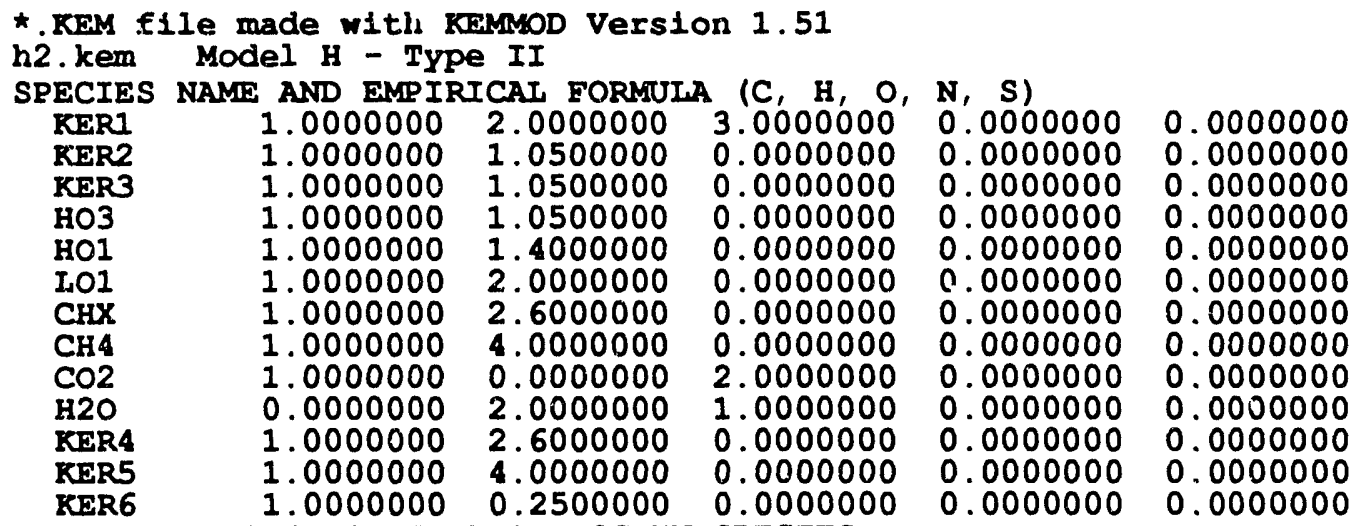

REIATIVE AMOUNT OF INITIAL TOC IN SPECIES

KER1 $\quad 0.0090000$

KER2 0.5000000

KER3 1.0000000

HO3 0.0500000

HOI 0.0500000

REACTION 1

1 RTACTANTS

KERI

2 PRODUCTS

$\mathrm{CO} 2 \mathrm{H2O}$

3 ENERGIES

$\begin{array}{lll}2.50000 \mathrm{E}-01 & 5.00000 \mathrm{E}+13 & 4.70000 \mathrm{E}+04 \\ 5.00000 \mathrm{E}-01 & 5.00000 \mathrm{E}+13 & 4.90000 \mathrm{E}+04\end{array}$

2.50000E-01 5.00000E+13 5.10000E+04

FORMULA STOICHIOMETRY COEFEICIENTS

$-1.00000 \mathrm{E}+00 \quad 1.00000 \mathrm{E}+00 \quad 1.00000 \mathrm{E}+00$

MASS STOICHIOMETRY COEFFICIENTS

$\begin{array}{lll}-1.00000 \mathrm{E}+00 & 7.09549 \mathrm{E}-01 & 2.90451 \mathrm{E}-01\end{array}$

REACTION 2

1 REACTANTS

KER2

1 PRODUCTS

HO3

6 ENERGIES

5. $00000 \mathrm{E}-02$

2.00000E-01

4.70000E-01

2. $00000 E-01$

5. $00000 \mathrm{E}-02$

3. $00000 \mathrm{E}-02$

$4.00000 \mathrm{E}+13$

4. $70000 \mathrm{E}+04$

4. $00000 \mathrm{E}+13$

4. $00000 \mathrm{E}+13$

4. $00000 \mathrm{E}+13$

4. $80000 \mathrm{E}+04$

4. $90000 \mathrm{E}+04$

4.00000E+13 5.20000E+04

$-1.00000 E+001.00000 E+00$

MASS STOICHIOMETRY COEFEICIENTS

$-1.00000 \mathrm{E}+00$ 1.00000E+00

REACTION 3

1 REACTANTS

KER2

7 PRODUCTS

HOI IOI

6 ENERGIES

5. 00000E-02

2.00000E-01

4. 70000E-01

2. $00000 \mathrm{E}-01$

5. $00000 \mathrm{E}-02$

3. $00000 E-02$

STOICHIOMETRY

8. 00000E-01

7. $00000 \mathrm{E}-02$

1. 25000E-01

$3.00000 \mathrm{E}+00$

CHX CH4 KER4 KER5 KER6

3. $00000 \mathrm{E}+13 \quad 4.90000 \mathrm{E}+04$

3.00000E+13 5.00000E+04

$3.00000 \mathrm{E}+13 \quad 5.10000 \mathrm{E}+04$

$3.00000 \mathrm{E}+13 \quad 5.20000 \mathrm{E}+04$

$3.00000 \mathrm{E}+13 \quad 5.30000 \mathrm{E}+04$

3. $00000 \mathrm{E}+13 \quad 5.40000 \mathrm{E}+04$

CONSTRAINTS ARE FORMUIA RATIOS FOR ALL REACTIONS

HO/TOTAL OII.

CHX/TOTAL OIL

$\mathrm{CH} 4 /(\mathrm{CHX}+\mathrm{CH} 4+\mathrm{H} 2)$

KER5/KER4 
3.50000E+01 KER6/XRR4

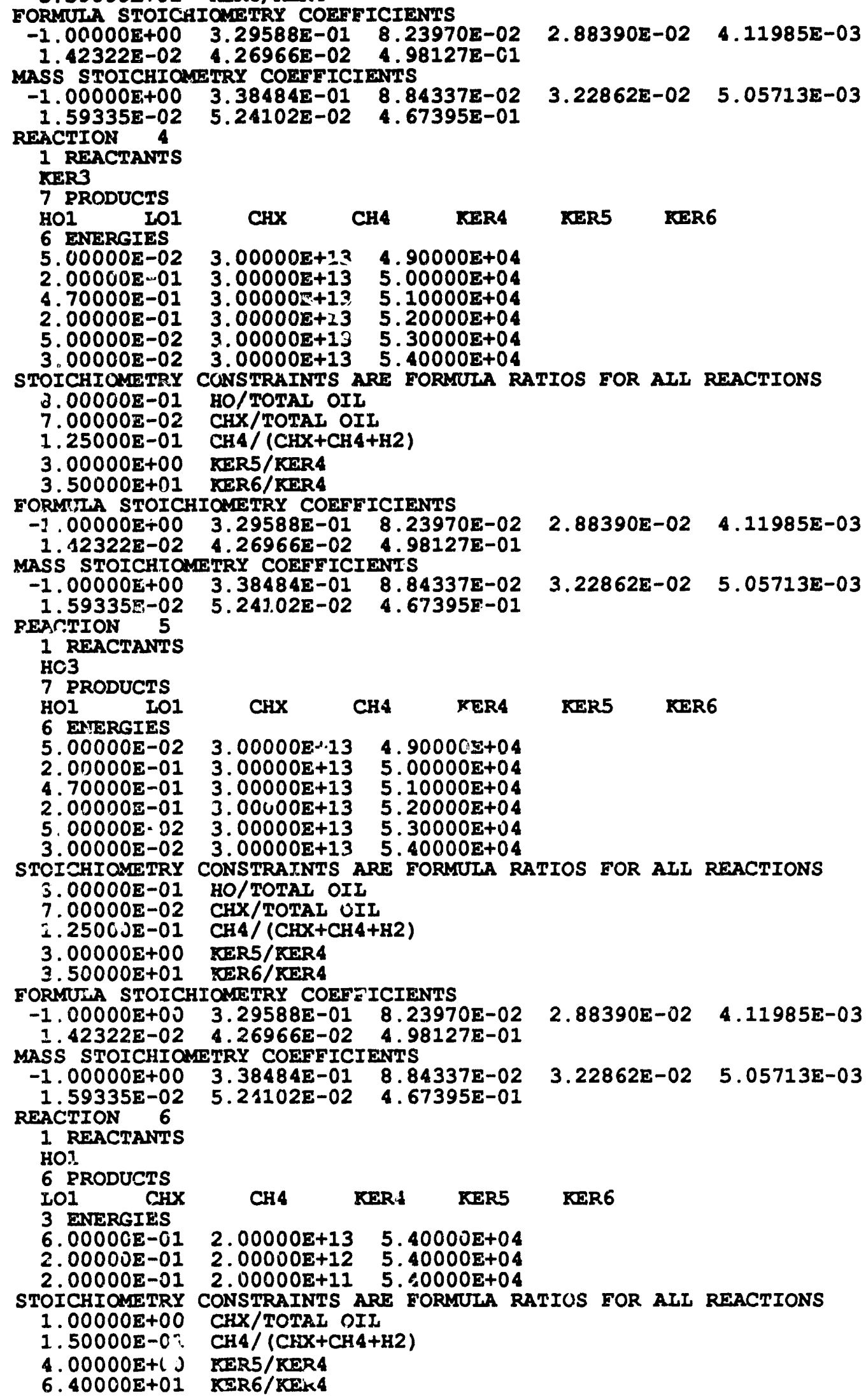




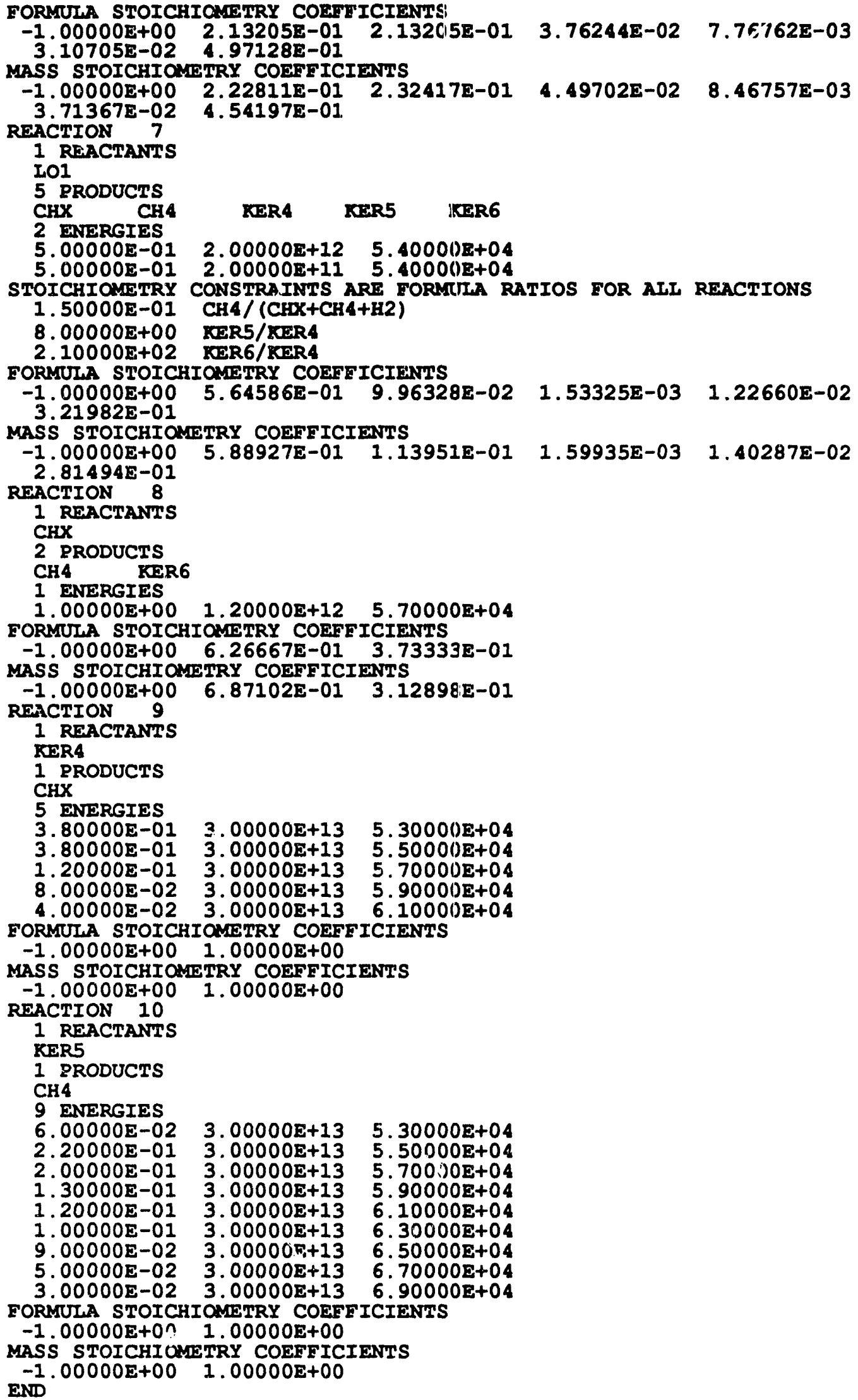


Table A4. Model $\mathbf{H}$ physical/chemical properties file for pressure-driven expulsion.

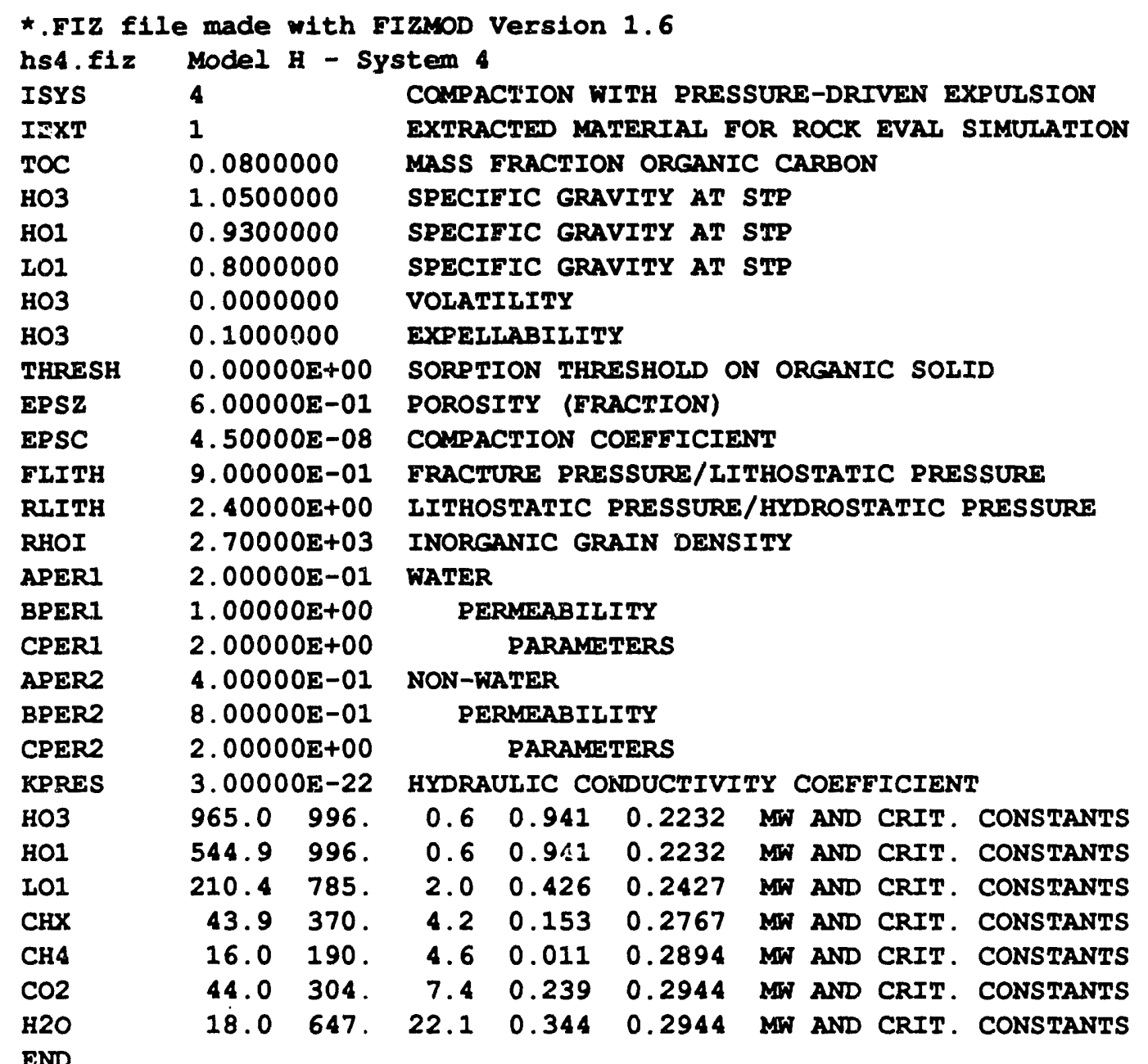



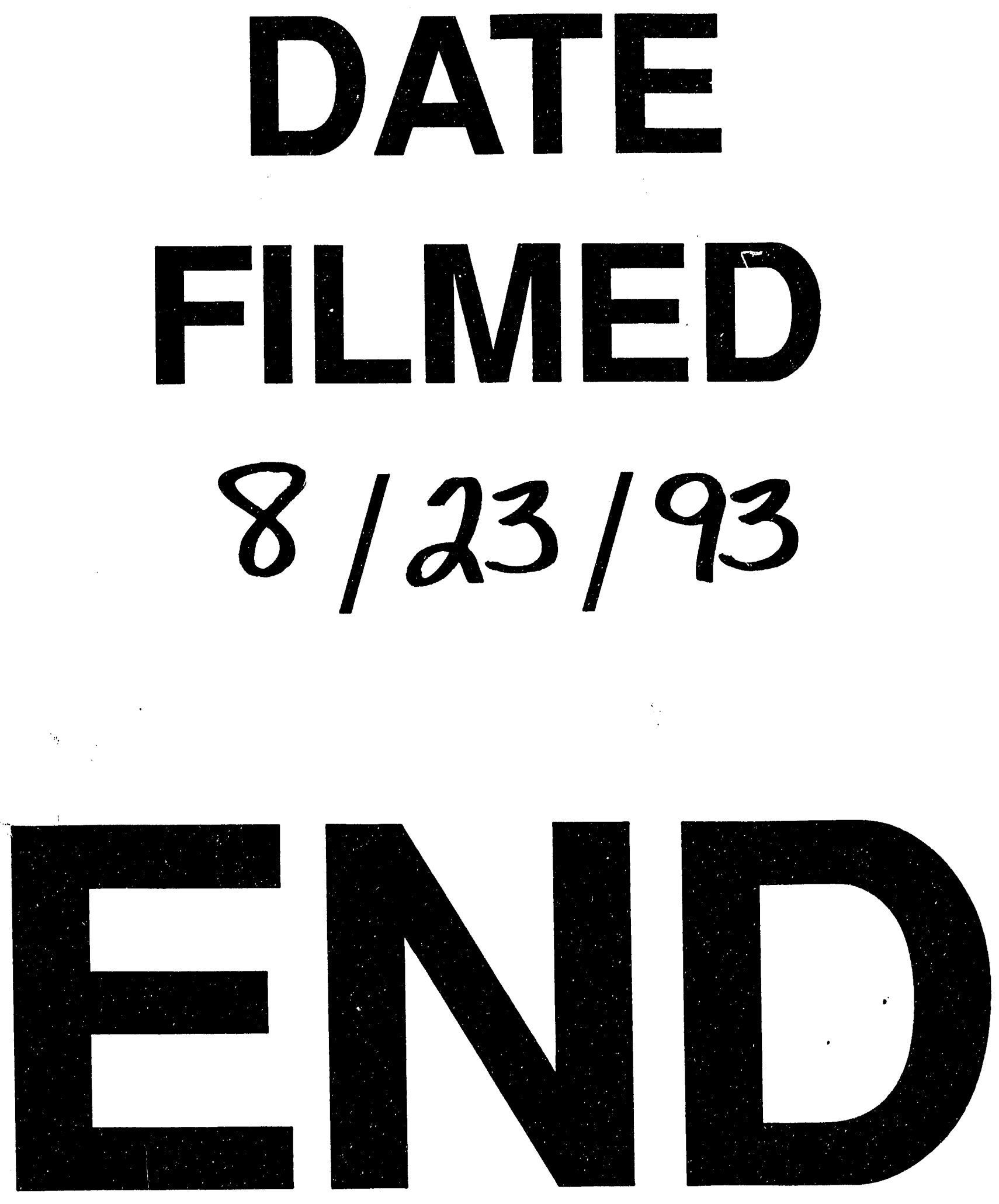
